\title{
Determinación de restos óseos de camélidos en dos yacimientos del Loa Medio (II Región)
}

IsABel CARTAJEnA $^{1}$

\section{RESUMEN}

El presente trabajo es una síntesis de la Memoria presentada para optar al Título de Arqueólogo (Universidad de Chile, 1993). Esta tuvo su origen en el Proyecto FONDECYT 792-89 "Un enfoque arqueozoológico para la identificación de camélidos sudamericanos" cuya investigadora responsable fue A. Benavente. Entre los objetivos propuestos en dicho proyecto figuró la identificación de diversos rasgos óseos que facilitaran la determinación de las cuatro especies de camélidos: llama (Lama glama), guanaco (Lama guanicoe), alpaca (Lama pacos) y vicuña (Vicugna vicugna). La contrastación de los patrones óseos, obtenidos de las muestras actuales con el material arqueofaunístico recolectado en dos yacimientos del Loa Medio (II Región), constituyó el motivo principal de la Memoria, con el fin de caracterizar el patrón cultural propio de los conjuntos faunísticos dejados por los antiguos grupos de cazadores y pastores. El estudio de los conjuntos arqueofaunísticos dentro del marco de la zooarqueología exige tanto la integración de la data cultural proveniente de la intervención humana que generó el registro, como la información biológica que se desprende del análisis de los restos óseos propiamente tales. Si bien no es posible tratar esta investigación en toda su extensión, se hace énfasis en lo que concierne a la determinación de especies de camélidos en registros arqueofaunísticos mixtos y a los resultados que se pueden obtener a través de la utilización del enfoque mencionado.

\section{ABSTRACT}

The present study is a synthesis of my thesis for a diploma of archaeology (Universidad de Chile, 1993) as part of a project sponsored by FONDECYT and called "An archaeozoological approach of identification of south american camelides". One of the issues of this project was the identification of osteological characteristics in order to determine the four species of camelides. The main purpose of my thesis was to oppose the osteological patterns -retrieved from current samples- with archeofaunistical remains found at two sites of the Loa Medio (II Region), aiming at a characterization of the cultural pattern that typifies the faunistical remains left by ancient hunters and herders. The archaeozoological study of the remains must include both cultural data based on human activity and biological information obtained by means of analytical study of the bones. The present study cannot cover the research as a whole, instead, it specially deals with the determination of the different species of camelides in mixed (domestic and wild) archaeofaunistic remains and results achieved through this approach.

1 Departamento de Antropología, Universidad de Chile, Santiago, CHILE.

\section{Introducción}

Abordar una investigación desde una perspectiva zooarqueológica, es decir, a través del estudio de las arqueofaunas, supone que se reconoce la importancia y significación de estos restos como parte de la evidencia cultural del pasado. Si bien se han acuñado una serie de definiciones acerca de los objetivos de la zooarqueología, Klein y Cruz Uribe (1984) señalan que su meta es reconstruir el ambiente y comportamiento de los antiguos grupos. Benavente (1989Ms, 1990Ms, 1992Ms-a) lo enmarca dentro de los enfoques interdisciplinarios y comparte la meta propuesta por Klein y Cruz Uribe, pero agrega la interrelación entre la información artefactual (que se puede obtener de los objetos que han sido transformados por el hombre) y los restos animales asociados a ella.

El análisis de los restos arqueofaunísticos desde esta perspectiva nos permite por una parte ordenarlos de acuerdo a un criterio biológico (p.e., determinar la composición de especies). Por otra parte, la rama cuantitativa permitirá la utilización de una serie de unidades de cuantificación de la arqueofauna que compone el registro. Finalmente, este enfoque hace posible relacionar y no perder de vista que la muestra está intervenida por el hombre $y$, por tanto, las variables culturales jugarán un rol importante. Esta intervención es el resultado de prácticas culturales que se traducen en una serie de modificaciones (marcas, fracturas, frecuencia relativa de unidades anatómicas u otras), las que contribuyen a la reconstrucción de los modos en que el animal es utilizado, producto de las estrategias implementadas por el grupo.

Por sus características, la zooarqueología puede ser considerada como un enfoque interdisciplinario. Muchas veces se ha entendido el rol del arqueólogo en un trabajo de este tipo como el de un sintetizador de una colección de informes de distintos especialistas, donde cada uno representa los intereses y prioridades de las diferentes disciplinas involucradas (Legge 1978). En zooarqueología, muchas veces 
estos informes no son lo suficientemente científicos como para satisfacer a los zoólogos, así como tampoco son lo suficientemente informativos como para satisfacer a los arqueólogos (Grigson 1978). Es por eso que el arqueólogo debe ser capaz de establecer y explicar los objetivos arqueológicos al especialista, el cual a la luz de éstos podrá entregar la información relevante para la investigación. Es necesario, por tanto, que el estudio de los restos óseos animales no quede aislado de las demás fuentes de información arqueológica (Legge 1978). En este sentido, un conjunto de restos faunísticos aislados no puede sustentar explicaciones en torno a la dinámica pasada que lo generó. Acceder por medio de esta subdisciplina a dicha dinámica sólo es posible a través de la capacidad de los arqueólogos para desarrollar cuerpos teóricos y metodológicos que, como señalan Haber y Ratto (1988: 2), les permitan reconstruir las diversas transformaciones sufridas por los elementos que componen el registro y que alguna vez fueron integrantes del sistema vivo. Las explicaciones a este proceso caen más bien dentro del marco de teorías específicas, donde un conjunto de elementos mantienen una configuración de relaciones particulares.

Desde esta perspectiva se abordará el estudio de los conjuntos arqueofaunísticos provenientes de dos yacimientos arqueológicos del Loa Medio, pertenecientes a grupos de cazadores recolectores y a pastores tempranos. El objetivo principal guarda relación con la determinación de especies de camélidos a través de la contrastación con patrones óseos actuales obtenidos por Adaro y Benavente (1990, 1992a, 1992b), Benavente y colaboradores (1990, 1993), Benavente (1992) y Benavente y Adaro (1992), aplicados a los conjuntos arqueofaunísticos mencionados. Este objetivo reviste especial importancia puesto que es la primera vez que se aplica este método de determinación taxonómica a un registro mixto (donde convergen especies domésticas y silvestres) en el norte de Chile en particular, y en el Area Andina en general.

El segundo objetivo se relaciona con el estudio de los conjuntos desde una perspectiva cultural a través del análisis de las modificaciones presentes en los restos arqueofaunísticos. Para tal efecto, se tratarán de aislar los agentes modificadores ya sean naturales y/o culturales. Una vez determinadas las modificaciones producto de la actividad humana, se asume que la información que se pueda obtener ya sea del estudio de marcas, de la anatomía económica (índices de utilidad), del análisis de fracturas, pre- sencia-ausencia de unidades anatómicas u otros, pueden contribuir a la caracterización del patrón cultural de ambos conjuntos arqueofaunísticos.

Por último, a través de los objetivos anteriores, se intenta diferenciar los patrones culturales presentes en ambos sitios, considerando esta vez el aspecto temporal. Es decir, observar el comportamiento de los conjuntos arqueofaunísticos a través del tiempo en dos situaciones contextuales diferentes. Una, caracterizada por un yacimiento arqueológico perteneciente a grupos cazadores recolectores tardíos asignables al Complejo Chiu Chiu (Benavente y Jackson 1992) cuya fecha más tardía se reconoce en $3625 \mathrm{AP}$, y otra, correspondiente a pastores tempranos con cerámica temprana (Benavente 1989Ms) con una fecha de $910 \pm 210 \mathrm{AC}$, ambos circunscritos al Loa Medio (II Región). El período cronológico que abarcan los sitios señalados está marcado por el paso de una subsistencia basada principalmente en la caza a otra basada en el control de animales domésticos. Las explicaciones para este período siguen básicamente dos líneas. Una que plantea que los primeros asentamientos de base agroganadera son el resultado directo de cambios adaptativos de grupos cazadores recolectores correspondientes al Arcaico Tardío, y aquélla que plantea la entrada de grupos procedentes de las Selvas Occidentales y este de Bolivia, los cuales se instalan tempranamente los oasis de San Pedro de Atacama, la hoya del Salar como también en el Loa Medio y río Salado (Benavente 1989Ms).

Determinar la presencia de restos de camélidos en sus formas domésticas y/o silvestres, en dos momentos y contextos diferentes, permitirá analizar el comportamiento que el grupo humano tuvo hacia el recurso animal y pesquisar los cambios ocurridos en él a través del tiempo. Se postula que los cambios que puedan percibirse a través de los restos óseos arqueofaunísticos de ambos yacimientos en la composición de especies, la forma en que son modificados los restos, unidades anatómicas presentes u otros, pueden ser interpretados como variaciones en el comportamiento del grupo humano hacia el recurso animal. Estos cambios obedecerían a la función zootécnica ${ }^{2}$ particular que le ha dado el hombre a las

2 Cardozo (1954: 70) señala que "el animal doméstico como todos los animales domésticos, es sede de funciones fisiológicas de las cuales depende la manutención de su vida misma. Algunas de esas funciones pueden ser utilizadas por el hombre, que empezó a aprovechar de ellas para sus 
especies utilizadas. Es decir, el animal es integrado como un elemento constitutivo de modo que determina, a través de sus requerimientos y utilidad, una forma particular de organización socioeconómica del grupo humano.

\section{Antecedentes}

Puesto que el objetivo principal de este trabajo es la determinación de especies de camélidos en yacimientos arqueológicos, es interesante discutir algunos estudios realizados a este respecto en el Area Andina.

Basados en los resultados obtenidos en el hemisferio norte (Europa y Cercano Oriente) en el campo de la determinación de especies, los arqueólogos que han trabajado en esta línea en el Area Andina, Noroeste Argentino o en la Patagonia han debido readaptar y redefinir los procedimientos metodológicos. Sin embargo, los intentos por identificar las distintas especies de camélidos en el hemisferio sur no han sido del todo satisfactorios.

Esto radica principalmente en que la determinación de camélidos para los Andes ha estado estrechamente relacionada con el problema de la domesticación debido a que esta familia presenta dos especies silvestres (guanaco y vicuña) y dos domésticas (llama y alpaca). La determinación, por tanto, es fundamental para esclarecer el problema de la domesticación. Sin embargo, son pocos los estudios que tratan directamente este problema. Muchos de ellos topan con él durante el estudio de restos arqueofaunísticos dirigidos en gran parte a la búsqueda de las causas de la domesticación, o el momento en que esta ocurrió. Para poder sustentar las inferencias obtenidas, se ha recurrido a la determinación de especiesde camélidos a través de distintos métodos, algunos de los cuales se presentan a continuación.

Herre (1952 cit. en Lownie 1978) es uno de los pioneros en tratar este problema. Trabaja con el supuesto de que el guanaco sería la forma ancestral de la llama y de la alpaca, ya que éste es el más grande de los camélidos. Cabe esperar que el primer cambio detectable con la domesticación tendría que ocurrir a nivel osteológico con la aparición de una forma de

propias necesidades. Las funciones fisiológicas de las que resulta una utilidad para el hombre o un servicio son las llamadas funciones económicas o, mejor dicho, 'funciones zootécnicas'." alpaca o llama de tamaño intermedio entre guanaco y vicuña (Wheeler et al. 1977a).

Más tarde este supuesto sería retomado por Wing (1972), quien interpretaría esta variación de tamaño como un indicador de domesticación. Para esta autora, una diferencia consistente está dada por la variación de tamaño entre estas cuatro especies. Cree que es posible encontrar parámetros de tamaño para cada una de ellas. En este punto está haciendo referencia al supuesto de Herre (1952) donde señala: "que el guanaco es el ancestro silvestre de ambas formas domésticas. Es interesante que ambas formas domésticas sean más pequeñas que su ancestro". Esta pérdida de tamaño que acompaña a la domesticación también fue notada en la domesticación de bovinos del Viejo Mundo (Grigson 1969; Wing 1971: 334; Higham 1986).

Hesse y Hesse (1979Ms, 1982) al tratar la domesticación y la incidencia que tendrían en ésta las oscilaciones climáticas en el Desierto de Atacama, retoman los resultados obtenidos por Wing. Los coeficientes de variación obtenidos por los autores para las medidas tomadas de la muestra son amplios y sugieren que los sitios estudiados presentan más de un tipo de camélidos debido a la presencia de un patrón bimodal.

Esta línea de investigación es continuada por Kent (1986), ya que al observar que Wing sólo logra aislar grupos (uno de tamaño grande que comprende guanaco y llama) y otro de tamaño pequeño (compuesto por vicuña y alpaca), trata de diferenciar dentro de cada grupo la especie doméstica y silvestre. A las medidas obtenidas se les aplicó un análisis discriminante por pasos ya que comúnmente hay uno o más grupos que difieren el uno del otro en varias características que muchas veces se traslapan y donde no se puede usar una sola característica para separarlos.

Por su parte Wheeler y colaboradores (1977a, 1977b) también trabajan en el campo del análisis arqueofaunístico en sitios precerámicos de Perú. Critican el método usado por Wing, argumentando que las diferencias de tamaño interespecies son lo suficientemente grandes como para empañar la delimitación de cada grupo. Sugieren la posibilidad de que puedan haber existido otras formas ancestrales de camélidos domésticos, cuestionando así la variabilidad presente en el análisis osteométrico como manera para distinguir entre las formas de camélidos domésticos y silvestres. 
Si bien existen otros trabajos para el Area Andina acerca del estudio de restos faunísticos pertenecientes a camélidos, subsiste aún una serie de problemas.

En este sentido, los primeros trabajos que comprenden el análisis de restos arqueofaunísticos pertenecientes a camélidos no tienen como objetivo principal la determinación de especies presentes en el registro. Están más bien insertos en el marco de la elaboración de periodificaciones, donde períodos como el Arcaico están definidos por una serie de logros, como, por ejemplo, la experimentación hortícola incipiente y el pastoreo inicial junto a una serie de otros rasgos (Núñez 1983: 55). Dentro de este ámbito, cobra creciente importancia dilucidar el problema de la domesticación, para lo cual se han utilizado una serie de modelos que describen la utilización del recurso animal que van desde la caza generalizada hasta el pastoreo de camélidos domésticos. La determinación, en este caso, cobra importancia en términos que sustenta las hipótesis sobre domesticación.

En este contexto se ha realizado una serie de intentos por diferenciar las cuatro formas de camélidos, apelando mayoritariamente al uso de medidas osteométricas. Este método ha demostrado que por sí sólo (tomando en cuenta solamente la variable tamaño) no es capaz de permitir una determinación confiable de especies.

Sin embargo, la mayoría de los autores reconoce que estas medidas se traslapan y que el límite entre ambos grupos no es claro, si bien este límite pudiera ser determinado, persiste aún el problema de diferenciar dentro de cada grupo las especies en particular. En este punto, se ha usado como un criterio discriminatorio la estructura de edad de los restos que componen el conjunto arqueofaunístico. El predominio de animales jóvenes se ha interpretado de acuerdo con los diferentes usos primarios que se le dan al animal (Wing 1972, 1975; Wheeler et al. 1977a, 1977b; Hesse y Hesse 1979Ms). Es así que el sacrificio de jóvenes sugeriría una economía productora de carne, propio de un grupo de pastores. Además, si la distribución de las edades no coincide con la forma en que ésta se da en poblaciones silvestres, también podría indicar la presencia de domesticación.

Es sabido que la estructura de edad presente en los restos dependerá de factores como estacionalidad, especialización zootécnica de los animales, variaciones que se están dando en las poblaciones silvestres, entre otros.

Otro problema derivado del análisis de medidas osteométricas, es el que guarda relación con la significación estadística de la muestra. Cuán grande debe ser la muestra para observar claras tendencias bimodales. Comúnmente nos encontramos con ejemplos como el planteado por Aschero y colaboradores (1991: 112), para el cual, la presencia de llama es sugerida por las medidas osteométricas obtenidas, pero la muestra es pequeña y carece de peso estadístico; y Yacobaccio (1991: 67), en donde, dado el estado fragmentario del conjunto y a la falta de especímenes que pudiesen ser medidos, obtiene resultados que no son representativos en términos estadísticos.

Indirectamente, en el punto anterior se toca el problema de la fragmentación, propia de los conjuntos arqueofaunísticos y de aquellas partes esqueletarias no fusionadas que dificultan las mediciones osteométricas. Aunque este método arroje buenos resultados, al ser aplicados a restos óseos actuales hay que considerar que éstos difieren de la data arqueológica. Algunos ejemplos de esta dificultad son aludidos por Wheeler y colaboradores (1977b: 97) al analizar los materiales faunísticos de Telarmachay, donde no logra identificar las especies de camélidos utilizados ya que hay muy pocos huesos de individuos adultos medibles.

Hesse y Hesse (1979Ms) también tropiezan con la misma dificultad; no pueden aplicar las medidas a las unidades tomadas originalmente por Wing y éstas son restringidas a los huesos de las patas. El problema es cómo diferenciar, por ejemplo, entre huesos cortos sin los puntos de fusión propios de huesos largos de animales jóvenes y de aquellos animales de tamaño pequeño.

Como se mencionó, Herre (1952 cit. en Lownie 1978) supone que el guanaco es el ancestro de las especies domésticas; se ha seguido trabajando básicamente con el mismo supuesto para la interpretación de los tamaños de las especies representadas. A este respecto no se han hecho muchos adelantos, sobre todo al tratar con la amplia variabilidad existente intraespecies, la que puede estar condicionada tanto por factores alimenticios como por manipulación genética, cuyo límite no es fácil de distinguir. Un ejemplo actual es el macho líder en hatos de llamas cuyo tamaño es sorprendentemente más grande en relación al resto del rebaño. 
Si bien se puede usar este método métrico para rastrear cambios que están ocurriendo producto de la manipulación del hombre, los estudios en el Viejo Mundo (acerca de los bovinos y ovinos) permiten afirmar el empequeñecimiento de las especies domésticas con respecto a las silvestres; en el caso de los camélidos domésticos, no se conoce el ancestro silvestre y, por consiguiente, su tamaño.

Estas dificultades se deben a que, en parte, las investigaciones arqueológicas se han centrado en la problemática de cazadores y que el registro arqueológico atribuible a "pastores andinos" está pobremente definido (Yacobaccio y Madero 1988: 64). A este respecto los trabajos de Núñez (1982, 1992), Hesse y Hesse (1979Ms), Benavente (1981, 1984, 1989Ms, 1990Ms, 1991, 1992Ms) y Yacobaccio y Madero (1988), entre otros, son de suma importancia para los avances en la investigación de dicho problema.

\section{Caracterización de los yacimientos}

El material arqueológico proviene de los yacimientos Chiu Chiu Cementerio (excavado en 1989, 1990) y Chiu Chiu 200 (excavado en 1988) ubicados en el sector del Loa Medio, II Región (Figura 1). Ambos sitios fueron excavados en función del proyecto "Un enfoque arqueozoológico para la identificación de camélidos sudamericanos" (FONDECYT 792-89), en el cual el objetivo fue la obtención de suficiente material cultural, necesario para la contrastación de patrones actuales (que permitiesen la determinación taxonómica de fanéreos y restos óseos) con material arqueológico.

\section{Chiu Chiu Cementerio}

Este yacimiento se encuentra ubicado a $2 \mathrm{~km}$ al suroeste del poblado de Chiu Chiu, en la II Región de Antofagasta.

La excavación, correspondiente a la temporada de 1989, logró aislar una estructura habitacional cuya superficie cubre $39 \mathrm{~m}^{2}$ mediante un sistema de $4 \times 3$ cuadrículas que abarcó un montículo con una depresión. Esta unidad habitacional se componía de un muro, como rasgo sobresaliente, el cual iba ganando altura según descendía la pendiente en donde están localizados estos montículos o estructuras, formando así una protección que resguardó a sus moradores de los fuertes vientos existentes en la localidad. El muro fue construido sobre la base de acumulación de arena, rocas y basura; y es justamente este último componente el que nos entrega un mayor volumen de información, puesto que en ella se encontraban contenidos una mayor variedad de restos óseos animales, fragmentos de cordelería y textiles, como también una enorme cantidad de material lítico (Ferraz 1992Ms-a: 2). La pendiente de dicha estructura hizo que el piso (con densa concentración de restos óseos, líticos, etc.) se deslizara hasta introducirse bajo el muro y sobre el cual éste se siguió levantando.

En 1990 se realizó una segunda excavación aislándose otra unidad habitacional. Además se delimitó un segundo sector relacionado con la estructura antes mencionada, que comprende una terraza expuesta con vista al valle del río Loa que abarca una superficie de $200 \times 300 \mathrm{~m}^{2}$. En este sector se identificaron siete depresiones de estructuras, de las cuales dos fueron excavadas. También se identificó para este sector un área focalizada de taller lítico, donde se realizó una recolección superficial. La estructura excavada se encontraba identificada por un área ennegrecida de forma ligeramente ovoidal y deprimida con un radio aproximado de $2 \mathrm{~m}$.

Jackson (1989Ms-a y 1989Ms-b), a través del análisis lítico, señala que Chiu Chiu Cementerio es asignable al complejo del mismo nombre, afinidad dada por la presencia de puntas lanceoladas (doble punta) y por sus microlitos, si bien ya no se encuentran las puntas lanceoladas grandes, propias de contextos más tempranos. Proliferan los microlitos, especialmente como perforadores, cuñas, piezas bipolares y raspadores entre otros. Estos indican una intensa actividad laboral en campamentos semiestables con actividades múltiples. Además presentan elementos de una industria pulimentada representada por trozos de malaquita trabajada y cuentas de collar, además de miniaturas zoomorfas.

Ferraz (1992Ms-a y 1992Ms-b), por su parte, también reconoce artefactos asignables al Complejo Chiu Chiu. Llama la atención la baja proporción de instrumentos funcionalmente especializados en el interior del campamento. Encuentra muchos instrumentos sobre lascas; dentro de éstos existe una alta proporción de piezas relacionadas con las actividades de manufactura (perforar, raer, raspar, cepillar) y en menor cantidad aquellas relacionadas con la caza y el destazamiento (tales como puntas de proyectil, cuchillos). Por otro 


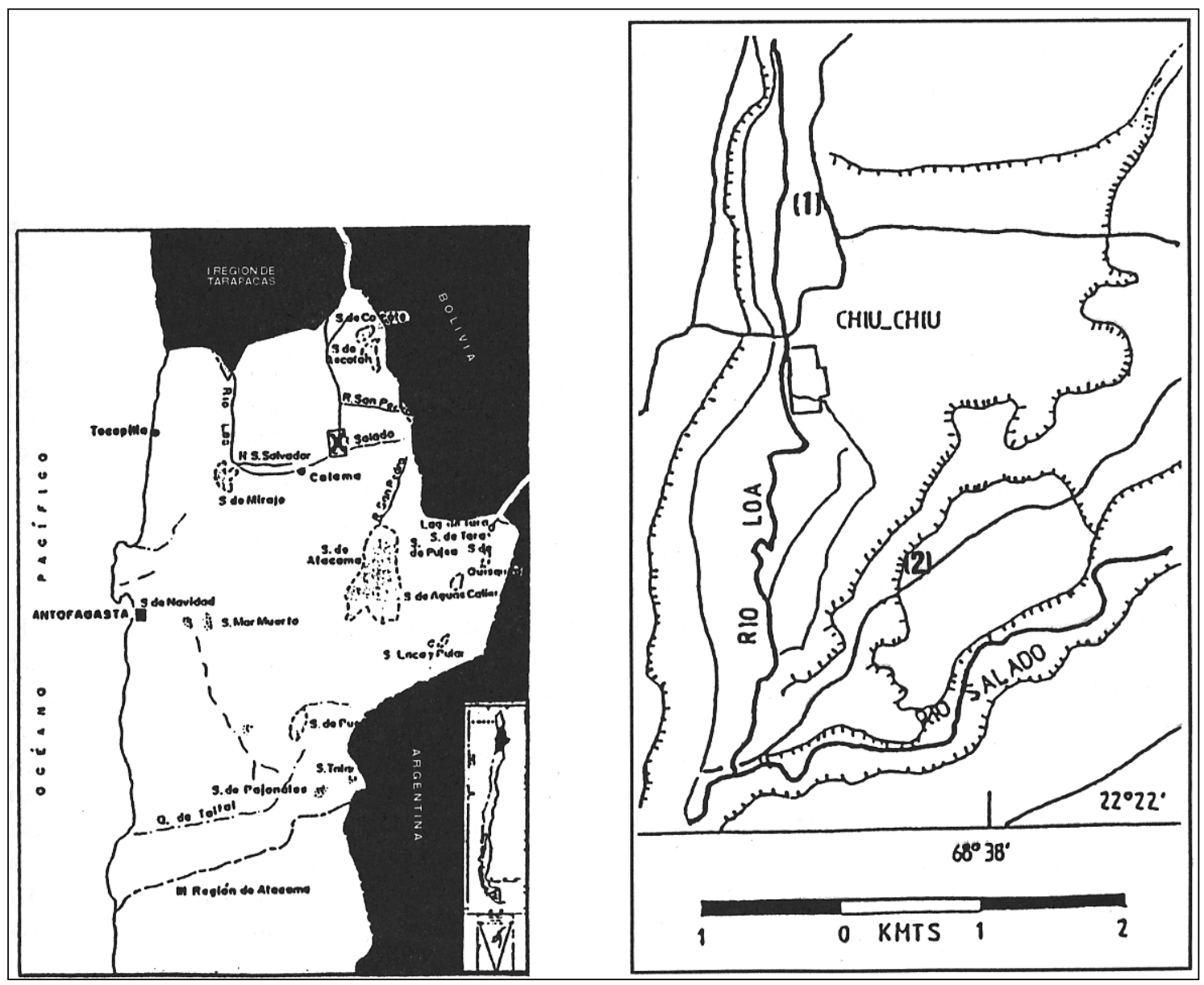

Figura 1. Ubicación de los yacimientos Chiu Chiu Cementerio y Chiu Chiu 200. El mapa inferior fue tomado de Arias y colaboradores (1992).

lado, existe un conjunto de artefactos relacionados a tareas de percusión (yunque, martillo, percutor) y artefactos destinados a actividades de molienda (estos últimos se encuentran fracturados y alcanzan escasa representación).

Además se constató la presencia de restos óseos humanos mezclados con los de camélidos que corresponden casi exclusivamente a extremidades y, de ellas, más de la mitad a pies y manos.

De lo anteriormente expuesto, podemos señalar que Chiu Chiu Cementerio, con una fecha de 2165 \pm 105 AC (obtenida por Druss para el sitio Ra LN 4-a nivel 2), se presenta como un campamento semipermanente concentrado básicamente en el recurso animal con actividades de manufactura múltiples.

El material arqueofaunístico analizado en este trabajo pertenece a la primera estructura habitacional excavada. De las cuadrículas trabajadas, ocho arrojaron abundante cantidad de material óseo (3250 especímenes) con un peso de $9.56 \mathrm{k}$.

\section{Chiu Chiu 200}

Este yacimiento está ubicado $700 \mathrm{~m}$ al noroeste del actual pueblo de Chiu Chiu en una explanada que corresponde a la terraza más alta de la ribera del río Loa, abarcando una superficie de $28693 \mathrm{~m}^{2}$.

El sitio fue excavado en sucesivas temporadas (1977 a 1979, 1986 a 1988) por Benavente, quien logró aislar unidades residenciales no perturbadas, pese a que el sitio presentaba una fuerte alteración producto de la remoción de materiales utilizados para la construcción de un poblado fortificado adyacente.

Los materiales analizados en este trabajo pertenecen a excavaciones realizadas durante 1988, ocasión en la que se lograron aislar tres unidades habitacionales que tampoco habían sido perturbadas. 
Ambas excavaciones dejaron al descubierto estructuras similares, típicas por su forma semicircular, a las cuales se asocian muros-basureros. En estos últimos se registra un amplio componente artefactual y ecofactual que incluye textiles, cestería, cerámica, líticos, restos óseos animales y otros. Benavente (1981, 1984) describe dichos muros como el aprovechamiento de ciertos sectores y desniveles del calcáreo, sobre el cual se ubican grandes piedras que sirven de base para éste. La basura está entremezclada en la porción superior del muro, ya que la pérdida de altura de este último, se compensa con redepositación continua de los derrumbes de piedras, los cuales van unidos en estas ocasiones a desperdicios.

La disposición de las unidades representaría un poblado aglutinado con un patrón constante, en cuanto a la construcción, orientación y disposición de las estructuras. A través del análisis de los restos ecofactuales y artefactuales, la autora concluye que se trata de un campamento de pastores tempranos, fechado en $910 \pm 290$ AC.

El conjunto lítico fue analizado por Jackson (1989Ms-a y 1989Ms-b) cuyos resultados arrojan una alta cantidad de talla (94\%) y sólo 5\% de pulida-piqueteada. En este último grupo existe un alto contenido de implementos de molienda que, según el autor, no es comparable a la frecuencia en que éstos se dan en sitios de cazadores recolectores. También se presentan instrumentos abrasivos relacionados con el trabajo de materiales blandos. Existe una baja frecuencia de puntas de proyectil respecto a cuchillos y raederas. Estas últimas se incrementan al considerar la frecuencia de lascas utilizadas como instrumentos de corte con filos vivos. Por tanto, plantea que no se trata de una comunidad cazadora, pero que sí depende de los productos cárneos de camélidos que fueron procesados con instrumentos cortantes.

La cerámica corresponde a los mismos tipos encontrados y analizados por Benavente (1981, 1984, 1988-89), caracterizados por tipos corrugados, incisos, pulidos, alisados, pintados, engobados $\mathrm{y}$ modelados.

La industria textil presenta una amplia variedad; vellones sin mayor trabajo, fibras torcidas, diferentes tipos de cordelería, trenzados, redes, mallas y tejidos planos dentro de los cuales se encuentra la "pelliza", emplumado y cruces con gasa, para los cuales se ha usado lana de vicuña, guanaco, llama, pelos de vizcacha, chinchilla y zorro (Benavente 1981, 1984,
1988-89; Arias et al. 1992). Este yacimiento se trabajó con un sistema de 4 x 10 cuadrículas de $1.5 \times 1.5 \mathrm{~m}$ de las cuales 26 arrojaron abundante material óseo (3511 especímenes) con un peso de $17055 \mathrm{k}$, el que fue utilizado para este trabajo.

\section{Planteamiento metodológico}

El planteamiento metodológico propuesto para poder alcanzar los objetivos, dentro de un marco de análisis zooarqueológico, abordó dos aspectos fundamentales:

1. Biológico. Permitirá la determinación de las especies de camélidos representadas en el registro a través de la comparación de los restos óseos con patrones base actuales.

2. Arqueológico. Permitirá reconocer el componente cultural que generó el registro.

La primera fase del análisis comprendió la identificación anatómica de los especímenes óseos con el fin de preparar y ordenar la muestra (Cartajena 1991Ms) para el siguiente paso, la determinación taxonómica, entendiéndose por ésta que "el espécimen identificado anatómicamente es considerado comparable con una parte esqueletaria de taxón previamente establecido" (Mengoni 1988a: 79).

El método utilizado para esta etapa consiste en la contrastación de los patrones diferenciales interespecies obtenidos por Benavente y colaboradores (1990, 1993) y Benavente y Adaro (1992) con los restos faunísticos provenientes de los sitios arqueológicos mencionados.

Para lograr dichos patrones, los esqueletos actuales pertenecientes a las cuatro especies de camélidos fueron analizados, haciendo una comparación interespecie de la morfología ósea externa entre cada una de las distintas partes que conforman el esqueleto axil y apendicular. Estos patrones son descritos en el Manual osteológico de camélidos sudamericanos (Adaro y Benavente 1992a, 1992b).

El método aquí planteado tiene la ventaja de una utilización conjunta de los indicadores. Si bien en algunas unidades anatómicas se presenta más de un rasgo, en aquéllas donde se trabaja sólo con uno, la determinación puede ser ratificada por los resultados obtenidos en otra unidad anatómica; ya que además, el método se estableció para las cuatro especies de 
camélidos en su conjunto. Por tanto, cada indicador presente en cada unidad anatómica puede ser visto en forma comparativa, siendo éstos concluyentes.

Otro aspecto abordado en esta primera etapa fue la estructura de edad del conjunto estudiado. Se persigue estimar la edad de los animales en el momento de su muerte, con el fin de confeccionar los perfiles etarios que permitan establecer la frecuencia que le corresponda a cada clase de edad, sobre las que se centró la matanza o sacrificio de animales, relacionadas directamente con las estrategias adaptativas implementadas por los grupos humanos.

Como criterio para la determinación de la edad de los especímenes se trabajará con la fusión de las epífisis. Este método se basa en el desarrollo esqueletario, el cual pasa por una serie de etapas de maduración, las que pueden ser reconocidas por el grado de fusión de las distintas partes que constituyen cada hueso. La secuencia de reemplazo, brote y desgaste de dientes en maxilares y mandíbulas pueden ser utilizados como criterios alternativos. Sin embargo, dadas las características de la muestra se trabajará fundamentalmente con el primer criterio. Al respecto se ha realizado una serie de trabajos para evaluar los criterios de estimación de edad de camélidos (Pacheco et al. 1979; Wheeler y Mujica 1981Ms; Wheeler 1982; Kent 1986; Herrera 1988).

De estos métodos se decidió utilizar las tablas de fusión de Wheeler y Mujica (1981Ms), elaboradas para camélidos en general, para la asignación de edad a los restos de camélidos no identificados y a las llamas (ya que muchas de las observaciones de los autores fueron realizadas en llamas); y en el caso que se determinen guanacos, serán tratados por los criterios establecidos por Herrera (1988).

Sin embargo, para caracterizar el conjunto en general es útil el método planteado por Wing, quien definió ocho estadios de fusión (1972: 330, Tabla 2). La información obtenida permite dividir los especímenes del conjunto en dos grandes categorías: fusionados (adultos) y no fusionados (jóvenes); su posterior graficación ayuda a observar la representación que alcanzan en los diferentes estadios.

Los pasos que siguen guardan relación con la caracterización de los conjuntos arqueofaunísticos desde la perspectiva cultural. Al trabajar con las modificaciones (fracturas, marcas u otras) hay que considerar que éstas comienzan desde el momento en que el animal muere hasta que alcanza un estado depositacional, resultado de una serie de procesos activos. Durante dichos procesos se conjuga un conjunto de agentes modificadores, tales como animales, transformaciones químicas o la interferencia cultural con la aplicación de procesos tecnológicos.

Por tanto, es necesario entender los procesos que han afectado al registro arqueológico, desarrollar métodos para reconocerlos y, una vez aislados, estimar cómo habría sido el registro original (Binford y Bertram 1977), lo que a través de un estudio tafonómico permitirá reconocer los componentes culturales.

Con este fin, primero es necesario precisar los aspectos sobre el proceso de formación del registro, para lo cual se ha utilizado la propuesta de Schiffer (1976). Luego se examinará el grado de integridad del registro a través del estudio de la densidad y los estados de meteorización del conjunto.

Para medir la densidad se tomó la propuesta de Yacobaccio (1991: 38) donde se correlacionan los valores de densidad global tomados de Lyman (1985, Tabla 1) con las unidades anatómicas mínimas (MAU). ${ }^{3}$

Por su parte, el grado de meteorización comprende diferentes estados progresivos de descomposición, los que pueden ser reconocidos a través de un criterio descriptivo propuesto por Behrensmeyer (1978).

También se consideraron las alteraciones térmicas ya que la presencia de restos óseos quemados tiene relación con la actividad humana; como preparación de alimentos, descarte producto del consumo y/o utilización como material de combustión. Por una parte, el fuego puede destruir el material óseo y alterar significativamente la estructura anatómica cuantitativa de los conjuntos; pero, por otra, la distribución espacial de los especímenes quemados puede sugerir los patrones y mecanismos de acumulación y descarte practicados por el hombre (Mengoni 1988a: 86).

Mediante el estudio de la ubicación de los restos óseos se intentará, por un lado, aislar eventos depositacionales y sus características; por otro, ver si la

\footnotetext{
MAU: Es la razón entre el valor del MNE (número mínimo de elementos identificados por taxón) y la frecuencia de la correspondiente unidad anatómica en el esqueleto completo.
} 
localización está relacionada de alguna forma con los estados de meteorización del conjunto; y por último, observar los posibles patrones de descarte.

El estudio de las marcas en los restos óseos es de gran importancia ya que las huellas dejadas por los artefactos humanos propios de actividades de desarticulación, faenamiento u otras en los materiales arqueofaunísticos, han sido utilizados como evidencia de situaciones interactivas (Mengoni 1988b).

Sin embargo, el hombre no es el único hacedor de marcas, ya que los animales también son reconocidos como agentes modificadores. El primer paso en la etapa de análisis de las marcas pretende aislar aquellas huellas resultantes de la acción de agentes no antrópicos. El hecho de poder atribuirlas al resultado de alguna actividad humana se basa en dos supuestos: que éstas se repitan en los diferentes especímenes en los mismos lugares y que exista alguna explicación anatómica para que las marcas se encuentren en un lugar determinado (Binford 1981). Es decir, un patrón de marcas humanas se caracterizará por ser repetitivo y por señalar una ubicación compatible con alguna actividad por parte del grupo.

Algo similar sucede con el análisis de las fracturas; durante mucho tiempo se ha intentado aislar los indicadores que permitan discriminar si el origen de las fracturas es por causa natural o intencional y si éstas se produjeron cuando el hueso aún estaba fresco o en contextos depositacionales.

Autores como Haynes (1983) y Núñez y colaboradores (1987), entre otros, han planteado una serie de criterios que permiten reconocer las fracturas de origen intencional. Al respecto, Cardich y Languens (1984) señalan que, efectivamente, se puede observar un patrón definido en la forma en que los especímenes animales son fracturados, ya sea para la confección de útiles o solamente para el aprovechamiento de la médula como fuente de alimento.

Al tratar de establecer dichos patrones de fractura, considero la definición que hace Mengoni (1982: 89), para quien éstos son "la síntesis cualitativa de los tipos de fractura que están presentes en los huesos de un conjunto dado".

Por otra parte, la zooarqueología ha desarrollado una rama cuantitativa que le permite medir, entre otras cosas, la abundancia relativa entre taxones, extrapolar a partes del conjunto muestreado la estructura del conjunto muerto y determinar en qué medida la abundancia taxonómica y anatómica reflejan aspectos del comportamiento cultural (Mengoni 1988a: 92) a través de la utilización de unidades de cuantificación y modelos de utilidad económica. Las unidades de cuantificación pueden ser utilizadas para el estudio de la "anatomía económica" del animal, donde el criterio de selección se hace sobre la base de la utilidad que reporta cada unidad anatómica en términos de su rendimiento de carne, grasa, médula o en general, para así poder inferir tendencias observables en el conjunto.

El último paso comprende la confección de una taxonomía numérica con el fin de caracterizar los conjuntos arqueofaunísticos de cada sitio a través del análisis de atributos tanto biológicos como culturales, para aislar aquellos patrones representativos de cada conjunto. Los resultados obtenidos aportan una serie de asociaciones que permitirán generar inferencias acerca de los registros estudiados y, por tanto, cumplir con los objetivos propuestos en cuanto a tipificar los conjuntos arqueofaunísticos de cada uno de los yacimientos.

\section{Resultados}

A continuación se presenta los resultados obtenidos en las diferentes etapas de análisis.

En cuanto a la determinación de especies, se puede concluir que el método utilizado de comparación de rasgos morfológicos, por una parte logró un alto nivel de identificabilidad taxonómica de los especímenes óseos analizados, y por otra, pudo ser aplicado a la mayoría de las diferente unidades anatómicas (Tabla 1).

Este método permitió la determinación de tres especies de camélidos: guanaco, llama y vicuña. En un registro mixto, cobra especial importancia el hecho de que el método utilizado se estableció indistintamente para las cuatro especies de camélidos conocidas. Por tanto, cada indicador presente en determinada unidad anatómica puede ser visto en forma comparativa, siendo éstos concluyentes (Figuras 1, 2, 3, 4, 5 y 6).

De 13 individuos, dados por el número mínimo para Chiu Chiu Cementerio, ocho pudieron ser determinados taxonómicamente. En forma análoga, de 14 individuos representados en el sitio Chiu Chiu 200, 12 fueron determinados (Tabla 2). Esto permitió a 
ISABEL CARTAJENA

\begin{tabular}{|c|c|c|c|c|}
\hline \multirow{2}{*}{ Unidad anatómica } & \multicolumn{2}{|c|}{ Chiu Chiu Cementerio } & \multicolumn{2}{|c|}{ Chiu Chiu 200} \\
\hline & Total & $\%$ & Total & $\%$ \\
\hline Fémur & 40 & 3.72 & 61 & 4.77 \\
\hline Tibia & 70 & 6.52 & 68 & 5.32 \\
\hline Húmero & 50 & 4.65 & 75 & 5.86 \\
\hline Radiocúbito & 56 & 5.2 & 75 & 5.86 \\
\hline Metatarso & 27 & 2.5 & 10 & 0.78 \\
\hline Metacarpo & 36 & 3.35 & 29 & 2.26 \\
\hline Metapodios & 29 & 2.70 & 13 & 1.01 \\
\hline $1^{\mathrm{a}}$ Falange & 120 & 11.18 & 85 & 6.65 \\
\hline $2^{\mathrm{a}}$ Falange & 63 & 5.87 & 25 & 1.95 \\
\hline $3^{\text {a }}$ Falange & 26 & 2.42 & 7 & 0.54 \\
\hline Calcáneo & 15 & 1.39 & 21 & 1.64 \\
\hline Astrágalo & 32 & 2.98 & 24 & 1.87 \\
\hline Tarsianos & 31 & 2.88 & 33 & 2.58 \\
\hline Carpianos & 32 & 2.98 & 41 & 3.20 \\
\hline Sesamoideos & 1 & 0.09 & 7 & 0.54 \\
\hline Rótula & 8 & 0.74 & 18 & 1.40 \\
\hline Atlas & - & - & 4 & 0.31 \\
\hline Axis & 7 & 0.65 & 12 & 0.93 \\
\hline Vert. cervicales & 28 & 2.6 & 47 & 3.67 \\
\hline Vert. toráxicas & 9 & 0.83 & 19 & 1.48 \\
\hline Vert. lumbares & 9 & 0.83 & 18 & 1.40 \\
\hline Vert. coxígeas & 2 & 0.18 & 1 & 0.07 \\
\hline Vert. no identificadas & 50 & 4.65 & 85 & 6.65 \\
\hline Sacro & 5 & 0.46 & 6 & 0.46 \\
\hline Coxal & 43 & 4.00 & 50 & 3.91 \\
\hline Escápula & 60 & 5.59 & 69 & 5.39 \\
\hline Costillas & 151 & 14.07 & 275 & 21.50 \\
\hline Esternebras & - & - & 2 & 0.15 \\
\hline Cráneo & 64 & 5.96 & 71 & 5.55 \\
\hline Mandíbula y maxila & 10 & 0.93 & 27 & 2.11 \\
\hline Total & 1073 & & 1278 & \\
\hline
\end{tabular}

Tabla 1. Frecuencias relativas de las unidades anatómicas en ambos sitios

\begin{tabular}{|c|c|c|c|c|c|c|}
\hline \multirow[b]{2}{*}{$\begin{array}{l}\text { Unidad } \\
\text { anatómica }\end{array}$} & \multicolumn{3}{|c|}{ Chiu Chiu Cementerio } & \multicolumn{3}{|c|}{ Chiu Chiu 200} \\
\hline & Total & Determinadas & $\%$ & Total & Determinadas & $\%$ \\
\hline Escápula & 60 & 5 & 8.3 & 69 & 10 & 14.5 \\
\hline Húmero & 50 & 1 & 2.0 & 75 & 4 & 5.3 \\
\hline Radiocúbito & 56 & 2 & 3.6 & 75 & 6 & 8.0 \\
\hline Coxal & 43 & 9 & 20.9 & 50 & 9 & 18.0 \\
\hline Fémur & 40 & 4 & 10.0 & 61 & 11 & 18.1 \\
\hline Tibia & 70 & 1 & 1.4 & 68 & 2 & 2.9 \\
\hline Vert. cervicales & 28 & 14 & 50.0 & 47 & 20 & 42.5 \\
\hline Vert. toráxicas & 9 & 2 & 22.2 & 19 & 8 & 42.1 \\
\hline Vert. lumbares & 9 & 1 & 11.1 & 18 & 3 & 16.7 \\
\hline Sacro & 5 & - & - & 6 & 1. & 16.7 \\
\hline Cráneo & 64 & - & - & 71 & 1 & 1.4 \\
\hline Mand. y maxila & 10 & 1 & 10.0 & 27 & 5 & 18.5 \\
\hline
\end{tabular}

Tabla 2. Fragmentos determinados taxonómicamente en cada sitio. 
su vez una buena comparación entre los conjuntos arqueofaunísticos de ambos yacimientos. Por una parte, se pudo establecer que la composición de especies en ambos registros es muy parecida. Es así que la llama y el guanaco presentan una proporción similar, en contraposición a la vicuña, que está representada por un individuo para cada sitio. Por otra parte, la determinación taxonómica aportó interesantes resultados en cuanto a la variabilidad inter e intraespecies (Figuras 7 y 8).

Si bien para Chiu Chiu Cementerio los restos óseos de guanaco y llama presentan un tamaño bastante similar, en Chiu Chiu 200 se observa que los guanacos han aumentado de tamaño respecto al sitio anterior, a la vez que las llamas se presentan en dos tipos ya sea de gran tamaño o más bien pequeñas. Estas podrían corresponder a los tipos "llama grande de carga" y "llama común de tipo pequeño" propuestos por Wing (1975), sugiriendo que existen dos variedades diferentes representadas. De lo anterior se puede concluir que:

El tamaño de los restos óseos de las especies es variable $y$, por tanto, no es un indicador adecuado para la distinción entre especies silvestres y domésticas.

Si bien existiría un decrecimiento del tamaño debido a la domesticación, ya sea por la segregación del animal del resto (aislamiento genético), restricción de pastos u otros (Bender 1975), en el momento de la investigación no existen indicadores para evidenciar este problema.

Durante el tiempo comprendido entre un sitio y otro hay evidencias de tipo tecnológico que suponen un avance; por ende, se postula que este cambio también se puede haber dado en otras áreas como en una mejor manipulación genética. El hombre ha adquirido un gran dominio de la manipulación genética de la llama, obteniendo dos variedades de ésta. No obstante, aún no ha logrado la manipulación genética de la alpaca (Benavente 1992Ms). Como se puede observar, ha sido un proceso lento ya que han transcurrido casi mil años.

Como los cambios genéticos no son rápidos ni fáciles de determinar, muchas veces se recurre a indicadores más inmediatos como la estructura de edad, puesto que la composición del rebaño sería el primer efecto de la domesticación. Se asume que la frecuencia de animales jóvenes se asocia a la presencia de animales domésticos, ya sea por su utilización en función de la producción de carne, mortalidad por condiciones de poca higiene en los corrales durante los primeros meses, o porque no corresponderían a los perfiles de edad de las poblaciones silvestres (Wing 1972, 1975; Wheeler et al. 1977a, 1977b; Pires-Ferreira et al. 1977; Hesse y Hesse 1979Ms). Sin embargo, basados en la estructura de edad de los conjuntos arqueofaunísticos analizados (Tablas 3 y 4), éstos están caracterizados predominantemente por animales adultos. Esto sugiere más bien la crianza de animales para funciones específicas (lana y transporte). Por tanto, la estructura de edad es un rasgo que ayuda a caracterizar los conjuntos pero no es un rasgo definitorio para establecer la presencia de especies domésticas o silvestres.

De lo expuesto se puede concluir que el método de patrones referenciales utilizado para la determinación de especies (Benavente 1989Ms, 1990Ms, 1992Ms; Adaro y Benavente 1990, 1992a, 1992b) permite fehacientemente determinar las especies de camélidos utilizadas sin la necesidad de descansar en supuestos que varían de acuerdo a situaciones contextuales específicas como las ya tratadas. Sin embargo, muchos de estos criterios son útiles para la caracterización y obtención de inferencias acerca del

\begin{tabular}{|l|c|c|c|c|c|}
\hline \multicolumn{7}{|c|}{ Chiu Chiu Cementerio } \\
\hline Especie & NISP & MNI adulto & U. anatómica & MNI joven & U. anatómica \\
\hline Guanaco & 27 & 4 & Escápula I. & - & - \\
Llama & 12 & 2 & Isquion I. & 1 & Fémur Ds. \\
Vicuña & 1 & 1 & Fémur Ds. & - & - \\
\hline \multicolumn{7}{|c|}{ Chiu Chiu 200 } \\
\hline Guanaco & 39 & 4 & Fémur Ds.D. & 1 & Fémur Px. \\
Llama & 40 & 4 & Escápula I. & 2 & Fémur Px.I. \\
Vicuña & 1 & 1 & Radiocúbito px. & - & - \\
\hline
\end{tabular}

Tabla 3. Medidas de abundancia taxonómica (NISP, MNI). 


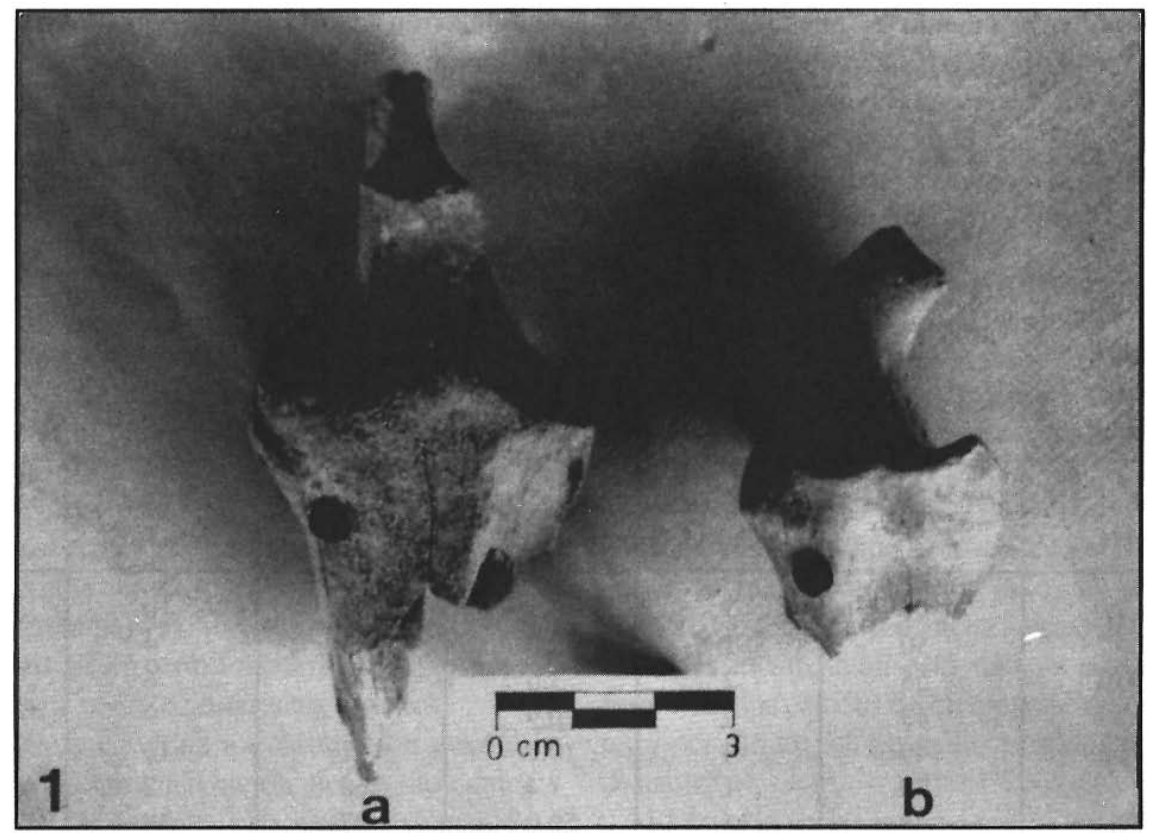

Figura 1. Determinación taxonómica de especies de camélidos. ${ }^{4}$
Radiocúbito proximal
a. Guanaco
b. Llama
Indicador
: Tuberosidad Lateral

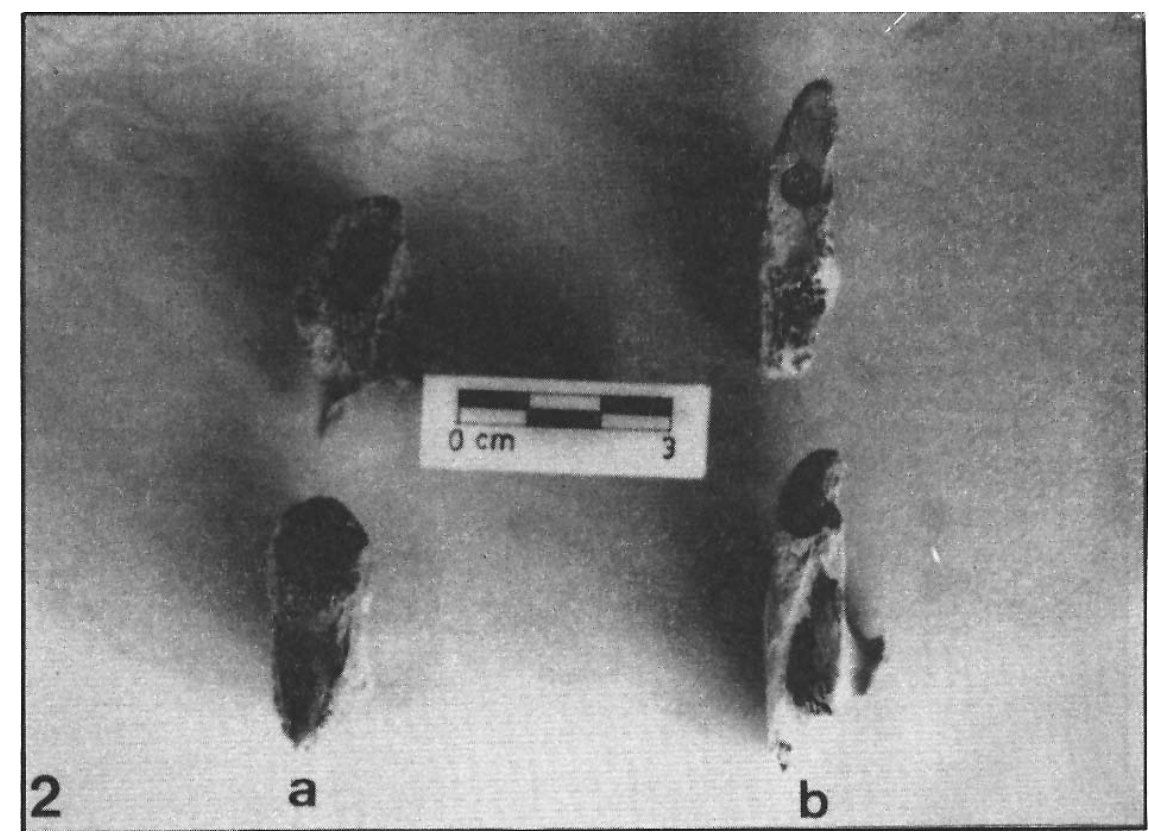

Figura 2. Determinación taxonómica de especies de camélidos.

Vértebras cervicales

Indicador
a. Guanaco
b. Llama
: apófisis articulares

4 Las Figuras 1, 2 y 3 corresponden a especímenes del sitio Chiu Chiu Cementerio. 


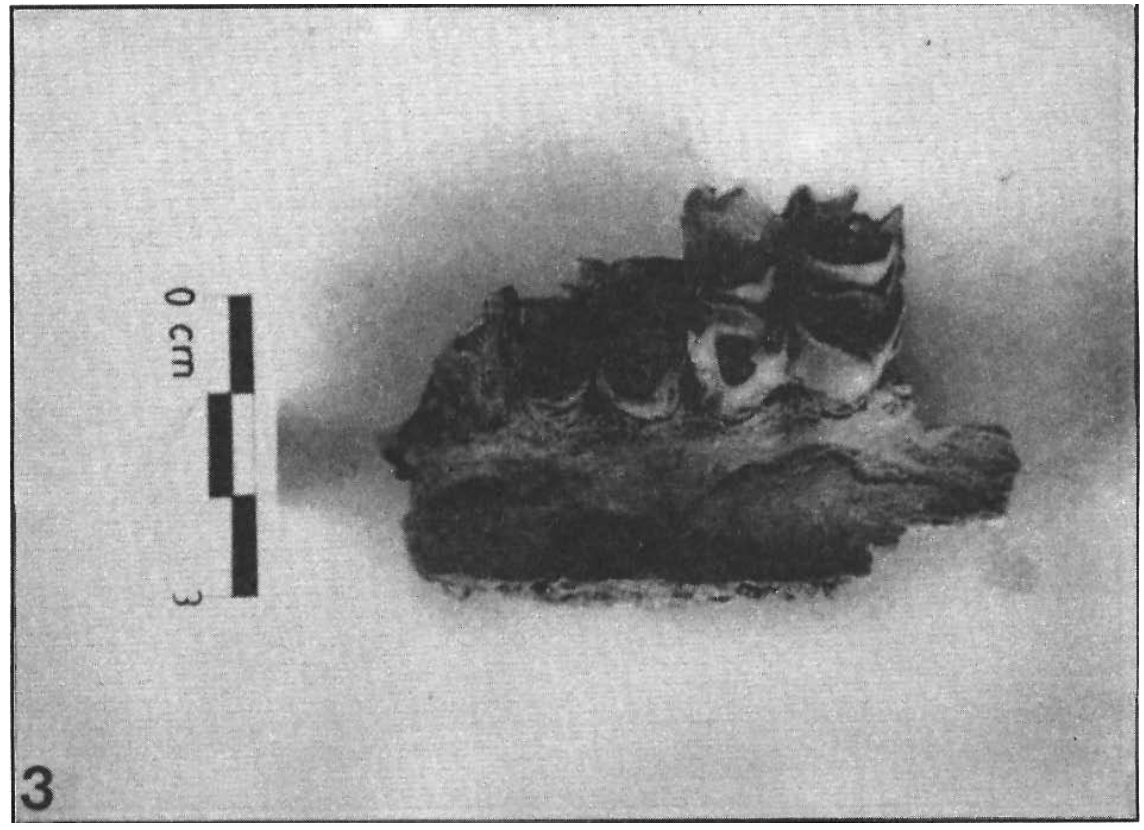

Figura 3. Determinación taxonómica de especies de camélidos.

$\begin{array}{ll}\text { Maxila } & \text { Llama } \\ \text { Indicador } & \text { : Línea de fusión de la arcada palatina }\end{array}$

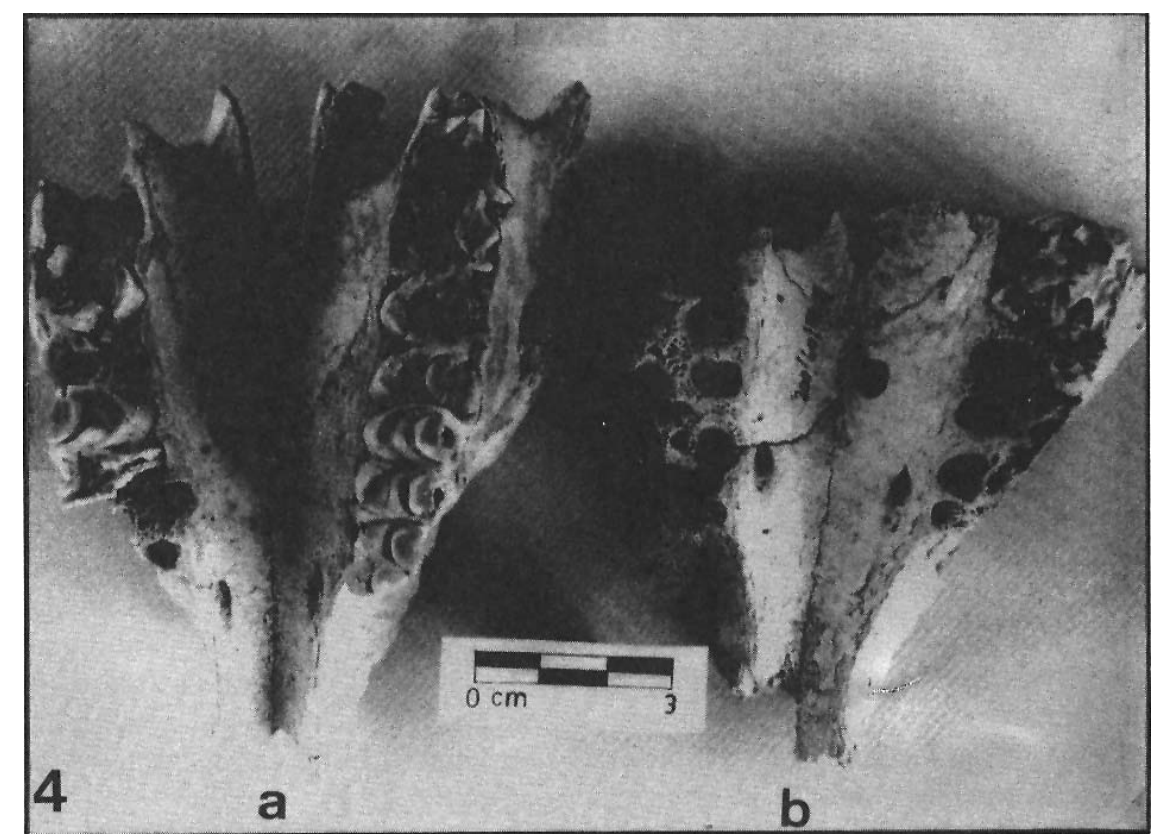

Figura 4. Determinación taxonómica de especies de camélidos. ${ }^{5}$

$\begin{array}{ll}\text { Maxila } & \text { a. Guanaco b. Llama } \\ \text { Indicadores } & \text { : Abertura en relación a la tuberosidad maxilar } \\ & \text { Arcada palatina }\end{array}$

5 Las Figuras 4, 5 y 6 corresponden a especímenes del sitio Chiu Chiu 200. 


\section{ISABEL CARTAJENA}

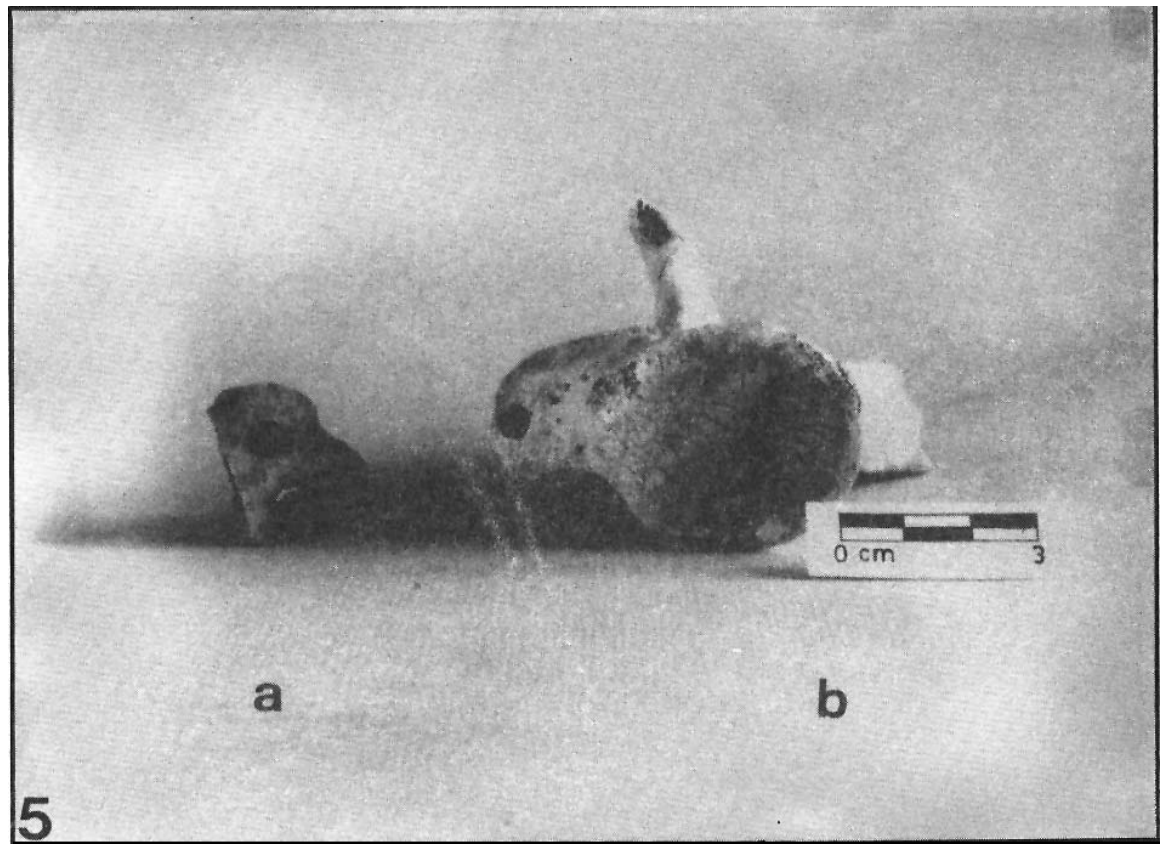

Figura 5. Determinación taxonómica de especies de camélidos.

$\begin{array}{ll}\text { Escápula } & \begin{array}{l}\text { a. Guanaco b. Llama } \\ \text { Indicadores }\end{array} \\ \begin{array}{l}\text { Tuberosidad escapular } \\ \text { apófisis caracoide }\end{array}\end{array}$

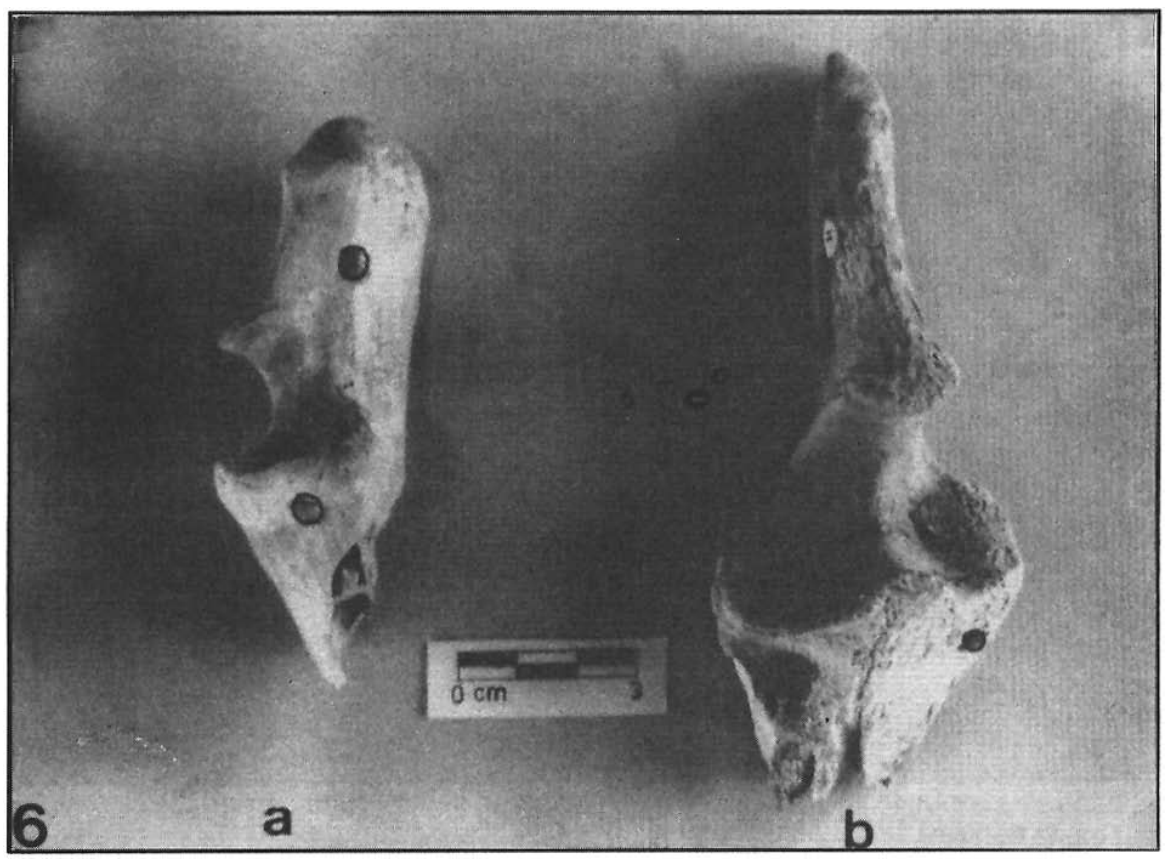

Figura 6. Determinación taxonómica de especies de camélidos.
Radiocúbito proximal
a. Vicuña
b. Llama
: Tuberosidad lateral
Indicadores
Olécranon 


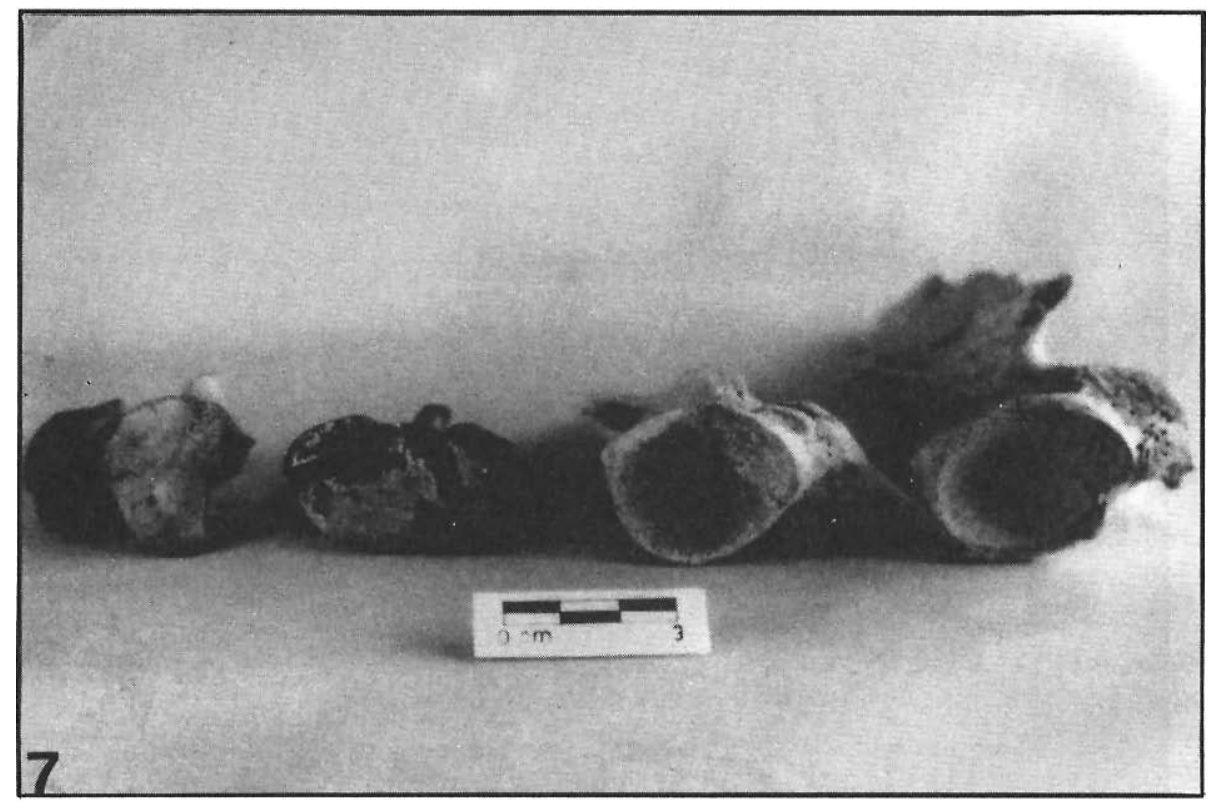

Figura 7. Escápula: Diferencia de tamaño interespecies. Las escápulas de la izquierda corresponden a guanacos provenientes de Chiu Chiu Cementerio y las de la derecha a llamas de Chiu Chiu 200.

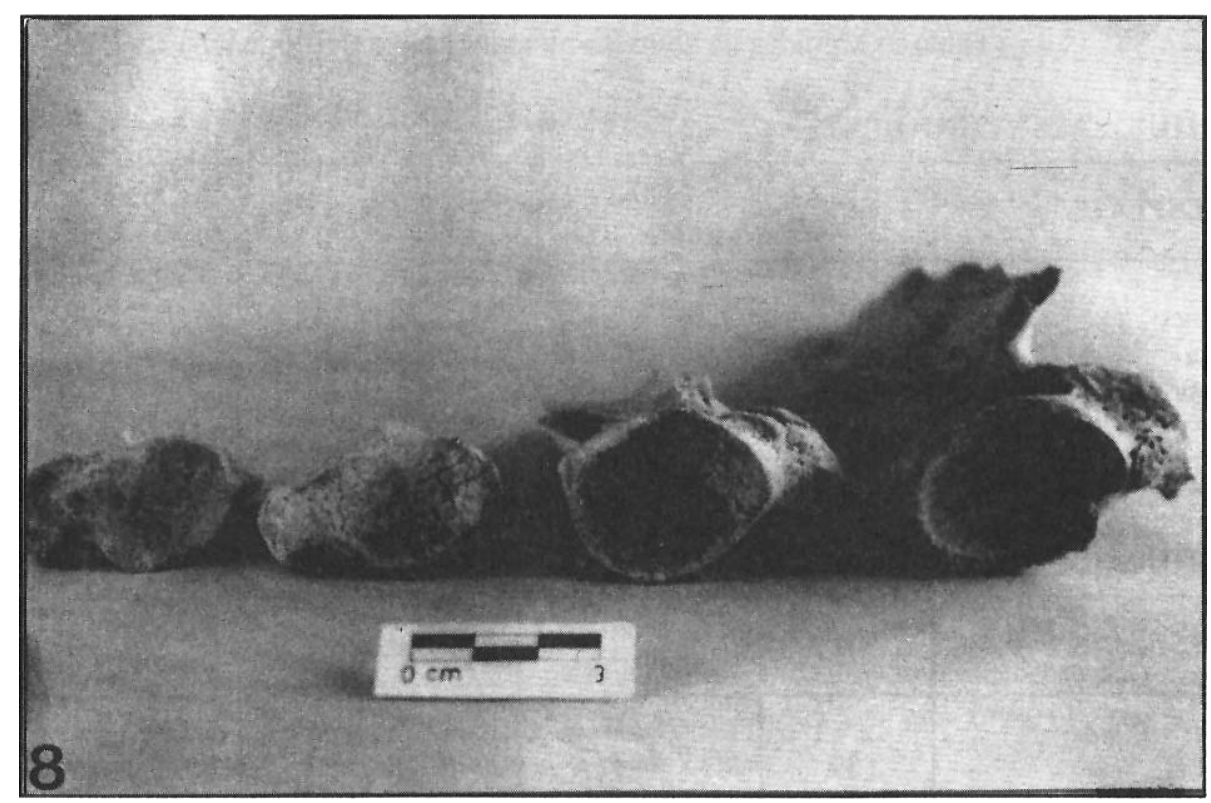

Figura 8. Escápulas: Diferencia de tamaño intraespecies. Las escápulas pertenecen a llamas de Chiu Chiu 200.

manejo del recurso animal (tipos de fractura, marcas, ubicación de los restos, frecuencia relativa, exposición al fuego, entre otros). No obstante, la determinación de especies en registros arqueológicos conlleva una serie de problemas metodológicos puesto que, a pesar de que existe una gran cantidad de unidades anatómicas que pueden ser identificadas, muchas de ellas no presentan rasgos diferenciales, dada la naturaleza del material arqueológico (fracturado, meteorizado, etc.). En la mayoría de los análisis se ha tratado el registro como perteneciente a camélidos en general. Sin embargo, muchos yacimientos como 


\begin{tabular}{|l|c|c|c|c|}
\cline { 2 - 5 } \multicolumn{1}{c|}{} & \multicolumn{2}{c|}{ Chiu Chiu Cementerio } & \multicolumn{2}{c|}{ Chiu Chiu 200 } \\
\hline Estados de fusión de Wing & Maduros & Inmaduros & Maduros & Inmaduros \\
\hline (0) Astrágalo & 32 & - & 24 & - \\
(1) Escápula & 18 & 2 & 24 & - \\
(2) Mtc, Mtt Px & 31 & - & 31 & 5 \\
(3) Tibia y húmero Ds & 72 & 19 & 70 & 3 \\
(4) Radiocúbito Ds & 27 & 1 & 24 & 1 \\
(5) Calcáneo & 15 & 4 & 14 & 14 \\
(6) Mtc, Mtt, Ds & 60 & 11 & 46 & 2 \\
(7) Fe Ds, 2 y 3 ${ }^{\circ}$ prem. reemplazados, & 18 & 5 & 26 & 15 \\
erupción 3 molar & 81 & 16 & 66 & 40 \\
(8) Fe, Ti, Hu, Rc Px & 354 & 77 & 325 & $(10.9 \%)$ \\
\hline Total fragmentos & & $(17.8 \%)$ & & 2 \\
\hline
\end{tabular}

Tabla 4. Estructura de edad de ambos conjuntos de acuerdo a los estadios de fusión establecidos por Wing (1972).

los analizados están representados por conjuntos mixtos; vale decir, la coocurrencia entre animales silvestres y domésticos. Lo anterior debido en gran parte a que los pastores generalmente implementarán dos estrategias para la obtención de carne; la explotación de camélidos mediante la caza y la matanza selectiva de animales del rebaño. Paralelamente, en áreas ubicadas junto a las vegas, las pasturas son igualmente atractivas para animales domésticos como también para silvestres. (Tablas 5 y 6 , Figuras 9, 10 y 11). A este respecto, los índices de utilidad fueron diseñados originalmente para poder predecir decisiones acerca del faenamiento y transporte de unidades desde el sector de matanza hacia los lugares de consumo. La frecuencia del tipo de unidades anatómicas encontradas podría reflejar el tipo de sitio en cuestión. Sin embargo, en los sitios estudiados, el lugar de matanza es el de consumo dada la cercanía de los animales domésticos, además del ingreso de unidades de trozamiento provenientes de animales silvestres. Por tanto, esta herramienta metodológica debe ser redefinida contemplando lo expuesto.

Durante el transcurso de la investigación se constató que el análisis zooarqueológico no puede considerar sólo el aspecto faunístico de la muestra aislado de las demás fuentes de información arqueológica. Si bien se reconoce que los restos arqueofaunísticos son el reflejo de las actividades de subsistencia dejadas por el hombre, no se pueden desarrollar métodos que le atribuyan significados a las variaciones de los conjuntos arqueofaunísticos separados del resto de los elementos que definen el contexto. Como señala
Bender (1975), los arqueólogos no trabajan con la información climática, geológica o zoológica, como tal, sino en relación al impacto que estos factores tienen en el comportamiento humano.

En lo que sigue, el esclarecimiento del contexto de cada yacimiento fue decisivo en la interpretación de cada registro arqueofaunístico. Desde esta perspectiva se entrega y se discute a continuación la información entregada por los sitios Chiu Chiu Cementerio y Chiu Chiu 200.

\section{Chiu Chiu Cementerio}

El estado de conservación del conjunto arqueofaunístico se presenta en muy buenas condiciones. No está afectado ni por el factor densidad ni por altos estados de meteorización, gracias a lo cual se obtuvo un alto nivel de identificación anatómica (Tabla 7).

La determinación taxonómica, por su parte, permitió identificar cuatro guanacos, tres llamas y una vicuña. Esto indica la coocurrencia en el registro tanto de formas domésticas como silvestres. Predominan los especímenes adultos (82.2\%); sin embargo los especímenes jóvenes representados por el número mínimo de individuos alcanzan un 23\%. La mayoría de los jóvenes se concentra antes de dos años y nueve meses. No fue posible detectar neonatos, sólo se puede decir que algunos no sobrepasan los nueve meses. De las especies identificadas todas corresponden a adultos, salvo un espécimen de llama que presenta menos de tres años y nueve meses. 


\begin{tabular}{|c|c|c|c|c|c|c|c|c|}
\hline \multicolumn{9}{|c|}{ Chiu Chiu Cementerio } \\
\hline U. anat. & $0-0.9$ & $0.9-1.9$ & $<1.9$ & $1.9-2.9$ & $<2.9$ & 2.9-3.9 & $<3.9$ & $>3.9$ \\
\hline $\mathrm{Fe}$ & & & & 4 & & & 3 & 27 \\
\hline $\mathrm{Hu}$ & _ & _ & 2 & _- & 2 & _- & _ & 39 \\
\hline $\mathrm{Ti}$ & - & . & 17 & 4 & _ & - & _- & 49 \\
\hline $\mathrm{RC}$ & 7 & . & - & . & . & _- & . & 42 \\
\hline $1^{\circ} \mathrm{Fal}$ & - & - & - & - & 19 & - & . & 101 \\
\hline $2^{\circ} \mathrm{Fal}$ & - & - & - & . & 9 & - & . & 54 \\
\hline Mete & - & - & - & - & 3 & - & - & 32 \\
\hline Mett & - & - & - & - & - & - & - & - \\
\hline Metp & - & - & - & - & 8 & - & - & 20 \\
\hline Esc & - & - & 2 & . & _ & . & _- & 58 \\
\hline $\mathrm{Cal}$ & - & - & 4 & - & - & - & - & 11 \\
\hline Total & 7 & - & 25 & 8 & 41 & - & 3 & 433 \\
\hline \multicolumn{9}{|c|}{ Chiu Chiu 200} \\
\hline $\mathrm{Fe}$ & . & . & 6 & . & . & . & 2 & 47 \\
\hline $\mathrm{Hu}$ & - & - & 4 & - & . & - & - & 65 \\
\hline $\mathrm{Ti}$ & - & . & - & 1 & . & - & 7 & 57 \\
\hline $\mathrm{RC}$ & 3 & - & - & - & - & - & 1 & 69 \\
\hline $1^{\circ} \mathrm{Fal}$ & . & . & - & - & 6 & - & . & 79 \\
\hline $2^{\circ} \mathrm{Fal}$ & - & - & - & - & 1 & . & . & 24 \\
\hline Mete & . & . & - & . & _- & . & . & 27 \\
\hline Mett & - & - & - & - & _- & - & . & 10 \\
\hline Metp esc & - & - & - & - & 2 & - & - & 1124 \\
\hline $\mathrm{Cal}$ & - & - & 1 & - & - & - & - & 14 \\
\hline Total & 3 & - & 12 & - & 9 & - & 10 & 427 \\
\hline
\end{tabular}

Tabla 5. Estructura de edad de ambos conjuntos de acuerdo a los criterios de Wheeler y Mujica (1981).

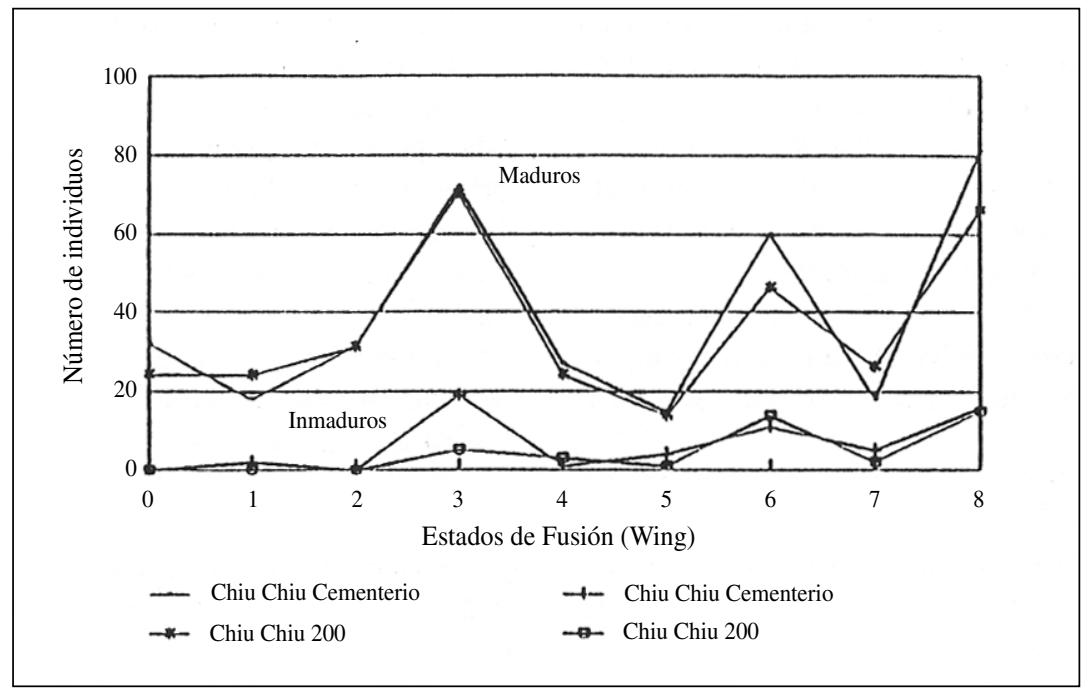

Figura 9. Estados de fusión: Número de individuos es equivalente al número de fragmentos por estado. 


\begin{tabular}{|c|c|c|c|c|c|c|c|c|}
\hline \multirow[b]{2}{*}{ Unidad anatómica } & \multicolumn{3}{|c|}{ Chiu Chiu Cementerio } & \multicolumn{3}{|c|}{ Chiu Chiu 200} & \multirow[b]{2}{*}{$\begin{array}{c}\text { DENS. GLOB } \\
\text { G/CM3 }^{1}\end{array}$} & \multirow[b]{2}{*}{ IUG $^{2}$} \\
\hline & MNE & MAU & $\% \mathrm{MAU}$ & MNE & MAU & \% MAU & & \\
\hline Cráneo & 2 & 2 & 20 & 3 & 3 & 26.0 & & 0 \\
\hline Maxila & 1 & 1 & 10 & 3 & 3 & 26.0 & - & 10 \\
\hline Mandíbula & 1 & 1 & 10 & 5 & 5 & 43.4 & 0.57 & 5.7 \\
\hline Atlas & . & _- & . & 2 & 2 & 17.39 & 0.13 & 8.8 \\
\hline Axis & 2 & 2 & 20 & 8 & 8 & 69.56 & 0.16 & 8.8 \\
\hline Vert. cervical & 13 & 2.6 & 26 & 21 & 4.2 & 36.52 & 0.19 & 51.3 \\
\hline Vert. toráxica & 4 & 0.33 & 3.3 & 10 & 0.80 & 6.95 & 6.24 & 21.1 \\
\hline Vert. lumbar & 4 & 0.57 & 5.7 & 12 & 1.7 & 14.78 & 0.29 & 44.9 \\
\hline Sacro & 2 & 2 & 2 & 4 & 4 & 34.78 & 0.19 & - \\
\hline Costillas & 30 & 1.25 & 12.5 & 47 & 1.95 & 16.95 & 0.40 & 100 \\
\hline Escápula & 15 & 6 & 60 & 17 & 8.5 & 73.91 & 0.36 & 38.4 \\
\hline Húmero Px & 5 & 2.5 & 25 & 8 & 4 & 34.78 & 0.24 & 23.8 \\
\hline Húmero Ds & 12 & 6 & 60 & 12 & 6 & 52.17 & 0.39 & 23.8 \\
\hline Radiocúbito $\mathrm{Px}^{3}$ & 15 & 7.5 & 75 & 23 & 1.15 & 100 & 0.36 & 7.8 \\
\hline Radiocúbito Ds & 13 & 6.5 & 65 & 10 & 5 & 43.47 & 0.43 & 7.8 \\
\hline Metacarpo Px & 6 & 3 & 30 & 4 & 2 & 17.39 & 0.56 & 1.3 \\
\hline Metacarpo Ds & 21 & 5.25 & 52.5 & 25 & 6.25 & 54.3 & 0.49 & 1.3 \\
\hline Carpianos & 31 & 2.21 & 22.1 & 40 & 2.85 & 24.78 & 0.39 & 1.3 \\
\hline Pelvis & 13 & 6.5 & 65 & 15 & 7.5 & 65.21 & 0.27 & 40.2 \\
\hline Fémur Px & 5 & 2.5 & 25 & 13 & 6.5 & 56.52 & 0.36 & 83.2 \\
\hline Fémur Ds & 10 & 5 & 50 & 12 & 6 & 52.17 & 0.28 & 83.2 \\
\hline Tibia Px & 9 & 4.5 & 45 & 14 & 7 & 60.86 & 0.30 & 21.3 \\
\hline Tibia Ds & 20 & 10 & 100 & 13 & 6.5 & 56.52 & 0.50 & 21.3 \\
\hline Metatarso Px & 9 & 4.5 & 45 & 5 & 2.5 & 21.73 & 0.55 & 1.7 \\
\hline Metatarso Ds & 12 & 3 & 30 & 7 & 1.75 & 15.2 & 0.46 & 1.7 \\
\hline Tarsianos & 31 & 3.1 & 31 & 33 & 3.3 & 28.69 & 0.39 & 1.7 \\
\hline Astrágalos & 18 & 9 & 90 & 19 & 9.5 & 84.82 & 0.47 & 1.7 \\
\hline Calcáneo & 14 & 7 & 70 & 13 & 6.5 & 56.52 & 0.64 & 1.7 \\
\hline $1^{\text {a }} \mathrm{Fal}$ & 48 & 6 & 60 & 43 & 5.3 & 46.08 & 0.42 & 2.1 \\
\hline $2^{\mathrm{a}} \mathrm{Fal}$ & 44 & 5.5 & 55 & 25 & 3.12 & 27.13 & 0.25 & 2.1 \\
\hline $3^{\mathrm{a}} \mathrm{Fal}$ & 22 & 2.75 & 27.5 & 7 & 0.87 & 7.56 & 0.25 & 2.1 \\
\hline Metapodios & 15 & 3.75 & 37.5 & 8 & 2 & 17.39 & & - \\
\hline Rótulas & 8 & 4 & 40 & 17 & 8.5 & 73.91 & _ & - \\
\hline Esternebras & - & - & - & 2 & 0.33 & 2.86 & 0.22 & - \\
\hline
\end{tabular}

1 Medida de densidad global (bulk density) (Lyman 1985, Tabla 2 en Mengoni 1982: 107).

2 Indice de utilidad de carne para el guanaco (Borrero 1986, 1988, en Yacobaccio 1991: 72).

3 Para los cálculos de densidad global se promedia en los valores del radio y del cúbito.

Tabla 6. MNE, MAU, \% MAU, Densidad global e IUG para el conjunto de camélidos en general en ambos sitios. 


\begin{tabular}{|c|c|c|c|c|c|c|}
\hline \multirow{2}{*}{$\begin{array}{l}\text { Llama } \\
\text { Unidad anatómica }\end{array}$} & \multicolumn{3}{|c|}{ Chiu Chiu Cementerio } & \multicolumn{3}{|c|}{ Chiu Chiu 200} \\
\hline & MNE & MAU & \%MAU & MNE & MAU & $\% \mathrm{MAU}$ \\
\hline Fémur Px & - & - & - & 2 & 1 & 28.57 \\
\hline Fémur Ds & 1 & 0.5 & 33.3 & 1 & 0.5 & 14.28 \\
\hline Tibia Px & - & - & - & 1 & 0.5 & 14.28 \\
\hline Húmero Px & - & - & - & 1 & 0.5 & 14.28 \\
\hline Radiocúbito Px & 1 & 0,5 & 33,3 & 4 & 2 & 57,74 \\
\hline Escápula & - & - & - & 7 & 3,5 & 100 \\
\hline Axis & - & - & - & 1 & 1 & 28.57 \\
\hline Cervicales & 3 & 0.6 & 40 & 4 & 0.8 & 22.8 \\
\hline Toráxicas & - & - & - & 5 & 0.41 & 11.7 \\
\hline Lumbares & - & - & - & 2 & 0.28 & 8 \\
\hline Coxal & 3 & 1.5 & 100 & 4 & 2 & 57.14 \\
\hline Maxila & 1 & 1 & 66.6 & 1 & 1 & 28.57 \\
\hline Mandíbula & - & - & - & 2 & 2 & 57.14 \\
\hline Cráneo & - & - & - & 1 & 1 & 28.57 \\
\hline \multicolumn{7}{|l|}{ Guanaco } \\
\hline Fémur Px & 1 & 0.5 & 20 & 2 & 1 & 33.3 \\
\hline Fémur Ds & 1 & 0.5 & 20 & 6 & 3 & 100 \\
\hline Tibia Px & 1 & 0.5 & 20 & 1 & 0.5 & 16.6 \\
\hline Húmero Px & 1 & 0.5 & 20 & 3 & 1.5 & 50 \\
\hline Radiocúbito Px & 1 & 0.5 & 20 & 1 & 0.5 & 16.6 \\
\hline Escápula & 5 & 2.5 & 100 & 3 & 1.5 & 50 \\
\hline Cervicales & 4 & 1.15 & 50 & 7 & 1.4 & 46.6 \\
\hline Toráxicas & 2 & 0.16 & 6.4 & 2 & 0.16 & 5.3 \\
\hline Lumbares & 1 & 0.14 & 5.6 & 1 & 0.14 & 4.6 \\
\hline Coxal & 5 & 2.5 & 100 & 4 & 2 & 66.6 \\
\hline Sacro & - & - & - & 1 & 1 & 33.3 \\
\hline Maxila & - & - & - & 1 & 1 & 33.3 \\
\hline Mandíbula & - & - & - & 1 & 1 & 33.3 \\
\hline \multicolumn{7}{|l|}{ Vicuña } \\
\hline Fémur Ds & 1 & 0.5 & 50 & . & - & - \\
\hline Húmero Ds* & 2 & 1 & 100 & - & - & - \\
\hline Radiocúbito Ds ${ }^{*}$ & 1 & 0.5 & 50 & - & - & - \\
\hline Metatarso Ds* & 1 & 0.5 & 50 & - & - & - \\
\hline Radiocúbito Px rótula* & - & - & - & 11 & 0.50 .5 & 100100 \\
\hline
\end{tabular}

*: No presentan indicadores para la determinación de especies pero por tamaño y morfología podrían corresponder a vicuña.

Tabla 7. MNE, MAU y \% MAU para cada especie. 


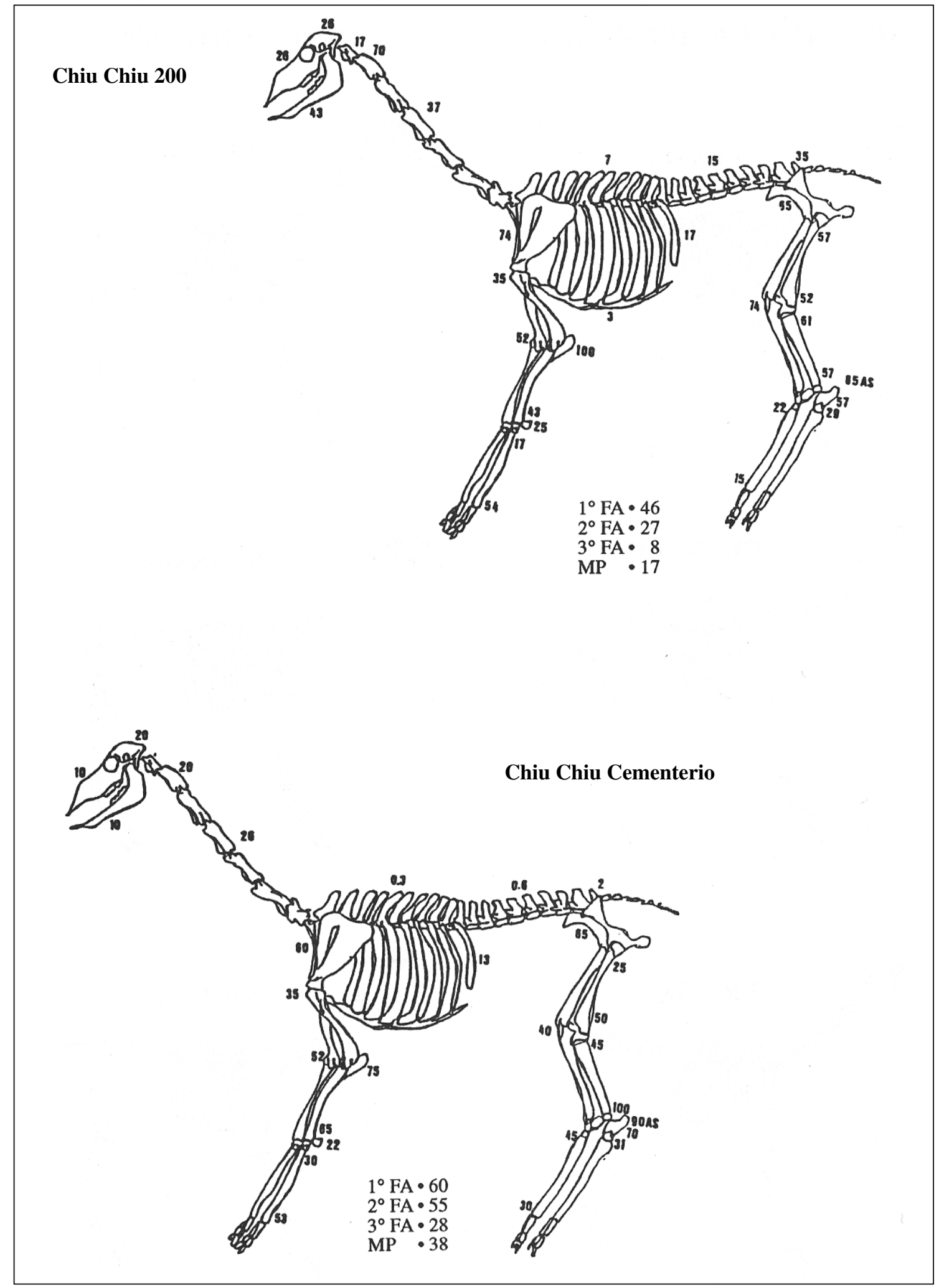

Figura 10. Representación del \% MAU para el total de restos de camélidos presentes en cada sitio. 


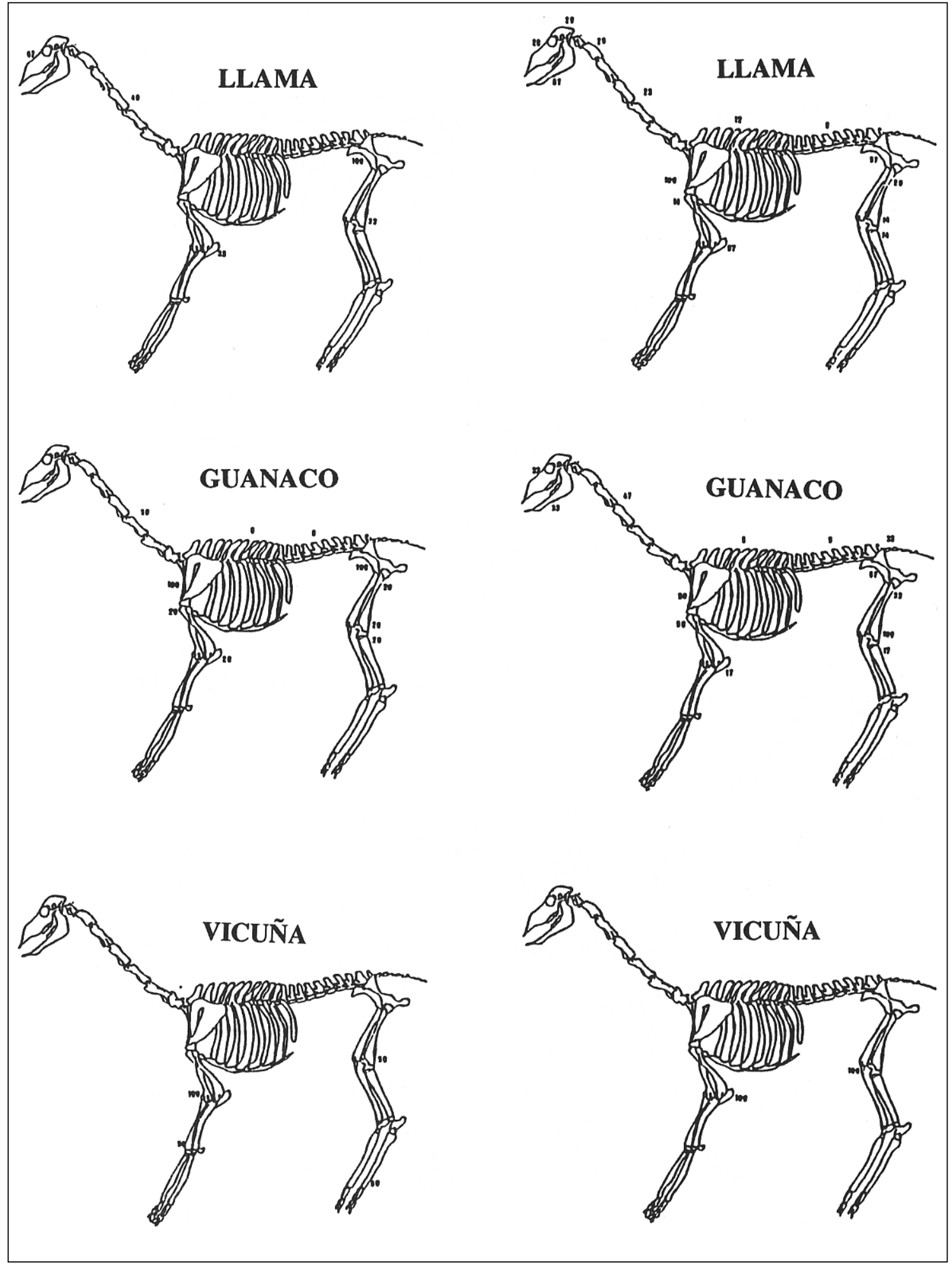

Figura 11. Representación del \% MAU para los restos de camélidos determinados taxonómicamente en cada sitio. 
De acuerdo a lo anterior, se puede inferir que la caza de animales silvestres sigue siendo una actividad predominante $\mathrm{y}$, a juzgar por la estructura de edad, el patrón refleja más bien la crianza de animales especializados. En el caso de las especies silvestres la estructura de edad coincide con la de las poblaciones silvestres.

Respecto al manejo de animales en función de la obtención de materias primas textiles, el análisis de fanéreos realizado por Arias y colaboradores (1992) determinó que las fibras de vicuña fueron las más utilizadas; en segundo lugar y en igual proporción aquellas de guanaco y llama, además de un roedor no precisado. Al parecer la llama no estaría solamente destinada a la producción de lana, puesto que las otras dos especies se encuentran disponibles para estas poblaciones que conocen bien la calidad de las fibras textiles.

El manejo en función de la producción de carne también parece improbable, puesto que vemos que hay gran cantidad de especies silvestres obtenidas mediante la caza, lo que parece reflejar más bien una "reticencia a matar los animales del rebaño" (Hesse 1986: 76). Las llamas muertas podrían obedecer a animales sacrificados por diversas razones como enfermedad, vejez u otros.

Si bien la subsistencia pudo ser complementada con la recolección vegetal, Ferraz (1992Ms-a, 1992Ms-b), a través del análisis de los artefactos de molienda, postula que el recurso vegetal debe haber sido de menor importancia para la subsistencia. Plantea que posiblemente se deba a un problema estacional. A este respecto, no se evidenciaron individuos neonatos que pudiesen acotar ocupaciones estacionales. Sí se puede decir con certeza que el sitio fue ocupado en los meses de otoño, invierno y primavera. La falta de recién nacidos podría señalar que el sitio no fue ocupado en verano, sin embargo sólo sabemos que los individuos son menores de nueve meses, algunos al parecer muy jóvenes.

Por otra parte, el yacimiento presenta vértebras de pescado y restos malacológicos, producto del intercambio con la costa y utilización de materias primas como obsidiana, fibras y pieles de vicuña (ya que existe poca representación de restos óseos pero alta utilización de esta fibra), lo que indica desplazamientos o contactos con la Puna. La coocurrencia de estos ítems dentro del registro sugiere más bien desplazamientos de algunos grupos o partidas de caza, mientras parte de la población ocupa el campamento residencial.

El análisis de las frecuencias de las unidades anatómicas traducidas a \% MAU permitió recuperar casi todas las unidades anatómicas (salvo atlas y esternebras), no obstante, con grandes diferencias porcentuales en su representación. La más alta representación la alcanzan la extremidad distal de la tibia, astrágalo y calcáneo; luego la escápula, el miembro anterior (patas altas), pelvis, el miembro posterior (patas altas) patas bajas, vértebras cervicales, cráneo, costillas $\mathrm{y}$, por último, con una muy baja representación, las vértebras lumbares y toráxicas.

Esto permite postular el ingreso de animales faenados cerca del lugar habitacional y aquéllos obtenidos mediante la caza lo que explica la presencia de unidades de alto y bajo rendimiento. Al parecer las unidades que entran son sometidas a faenamientos secundarios y consumo. El método de faenamiento habría sido la desarticulación, evidenciada por marcas cercanas a éstas. Hay una alta intencionalidad de fracturación de los huesos largos como lo demuestra la gran cantidad de fragmentos de diáfisis de huesos largos, astillas y especímenes con diversos tipos de fractura. Predomina la fractura longitudinal y en menor cantidad la transversal. Hay, ademas, una clara intencionalidad de fracturar las falanges; situación que en sitios más tardíos de la zona no es común (Pucara de Chiu Chiu: 1200 DC; Benavente com. pers. 1992).

Las actividades anteriormente señaladas son consistentes con los resultados obtenidos de los análisis líticos de Jackson (1989Ms-a, 1989Ms-b) y Jackson y Benavente (1989Ms, 1990Ms, 1992Ms) quien señala una alta proliferación de perforadores, cuñas, piezas bipolares, raspadores, cuchillos que indicarían actividades múltiples. Ferraz (1992Ms-a, 1992Ms-b) señala que existe una alta proporción de piezas sobre lascas relacionadas con actividades de manufactura (perforar, roer, cepillar) y en menor cantidad puntas de proyectil, cuchillos vinculados al destazamiento. Además, existe un conjunto de artefactos relacionados a tareas de percusión.

La ubicación de los restos sugiere que éstos fueron descartados en el piso depositacional y en los muros. Aquí se encuentran tanto los no quemados como quemados. Estos últimos alcanzan un 30\%. Pese a la gran cantidad de restos calcinados, no aparecen señales de un fogón al interior de la habitación, sólo hay 
evidencias de pequeños lentes de ceniza. Al parecer el lugar de preparación de alimentos se encontraría fuera de la unidad habitacional, los que podrían ser fogones "comunales". Esto podría explicar la baja representación de algunas unidades anatómicas. En experimentos realizados por Lanata (1988) se recuperaron unidades con valores de bajo rendimiento, siendo los de alto rendimiento los primeros en desaparecer en los fogones. Sin embargo, el lugar de consumo debió ser la unidad habitacional por la cantidad de restos calcinados encontrados. Por otra parte, las acumulaciones de cenizas e intencionalidad de arrojar desechos al fuego puede estar relacionada con la utilización de cenizas y grasas en el trabajo de los cueros (Yacobaccio 1991: 103).

La gran cantidad de restos óseos al interior de la estructura se asemeja a la cantidad de restos encontrados en tres estructuras habitacionales de Chiu Chiu 200 pertenecientes casi al mismo número de animales. Esto sugiere que las estructuras pudieron albergar un grupo mayor de personas por un período relativamente largo ya que las habitaciones son más grandes. Podría corresponder a grupos familiares extensos que comparten lugares para la preparación de alimentos. Tampoco existen evidencias de corrales, por lo que al parecer pastan conjuntamente en la vega.

El área de habitación, dada la densidad del piso ocupacional, sugiere que al interior se llevó a cabo una serie de actividades que puede estar relacionada con el trabajo de líticos. Ferraz (com. pers. 1992) señala una gran cantidad de desechos líticos al interior de las habitaciones producto del trabajo sobre artefactos preformatizados. Esto no implica que no existan otras áreas de actividad, como lo demuestra el sector en donde encontramos áreas ennegrecidas y un taller lítico "que se vincula directamente con el procesamiento de instrumentos destinados a las actividades de caza" (Jackson y Benavente 1990Ms: 8).

La menor frecuencia de puntas de proyectil en relación a los instrumentos relacionados con actividades de manufactura ha sido interpretada como una disminución de las actividades de caza. Sin embargo, cabe señalar que muchas de las puntas de proyectil fueron descartadas por estar fracturadas o dañadas. El resto puede haber sido transportada por los cazadores.

Junto a los restos óseos animales se encontraron restos óseos humanos (Munizaga 1992Ms). Estos representan un número mínimo de dos individuos de ambos sexos, adultos jóvenes o de mediana edad. Los restos corresponden casi exclusivamente a extremidades y de ellas más de la mitad a pies y manos, los pertenecientes a los pies es posible articularlos. Llama la atención la mezcla de éstos con los restos de huesos animales producto del descarte. Si se trata de un entierro secundario, éste fue contemporáneo al uso de la estructura, y dada la distribución de los restos óseos animales, ésta parece haber seguido siendo ocupada por el grupo. No se percibe tampoco un abandono de la estructura producto del entierro. Como antecedentes en el área sólo encontramos en Loa Oeste 3 "un esqueleto femenino y dolicoide que reposaba sobre la estructura y que debió corresponder a los últimos habitantes de ella" (Orellana 1971:21). Por otra parte, en la vertiente trasandina en el estrato E3 del sitio Huachichocana (Fernández Distel 1974) $7600 \mathrm{AC}$, se encuentra un entierro de tipo compuesto por procesos secundarios de reducción, disposición final con selección de piezas esqueletarias sobre todo del miembro inferior y un cráneo carbonizado y destruido en una envoltura de paja. No se puede obtener mayor información sobre los restos óseos, sólo su ubicación junto a los huesos animales y artefactuales de descarte, entre los cuales se encontró una mano de moler con ocre rojo.

De lo expuesto se concluye que Chiu Chiu Cementerio constituye un campamento semiestable con estructuras semicirculares no adyacentes, con una base de subsistencia basada en la caza de animales silvestres y en el manejo de la llama, con una fecha de 2165 AC.

\section{Chiu Chiu 200}

En general, se puede decir que el grado de identificabilidad anatómica de los especímenes fue alto. En gran medida debido a que el conjunto no estaba gravemente afectado por los factores de densidad, meteorización o acción de animales.

La determinación taxonómica, por su parte, permitió reconocer seis llamas, cinco guanacos y una vicuña. El conjunto está caracterizado por especímenes adultos (89.1\%); los jóvenes, en términos del número mínimo de individuos, constituirían un 28\%. La mayoría de los jóvenes están representados por especímenes menores de dos años y nueve meses. En el caso de las especies determinadas se encontraron dos especímenes pertenecientes a llama con una edad que fluctúa entre un año nueve meses y dos años nueve meses. Se identificó un espécimen de guanaco no mayor de dos 
años. El resto de los animales corresponde a adultos, si bien en este yacimiento aumentan los especímenes de llama, también aumentan los de guanaco, habiendo una coocurrencia casi de 50\% para cada especie. Este patrón demuestra que la caza sigue siendo importante en la subsistencia del grupo. El mantenimiento de un rebaño con animales adultos sugiere una función especializada de éstos. Las llamas presentes en el registro pueden deberse al sacrificio intencional de animales mañosos, viejos, enfermos, hembras estériles u otros (Miller 1977; Benavente 1981, 1984).

La función de la llama no estaría mayormente relacionada con una economía productora de carne, pues ésta es aportada por la caza. Respecto a la utilización de este animal para la confección textil, los estudios de Benavente (1981, 1982, 1989, 1990, 1992a) y Arias y colaboradores (1992) indicaron la utilización de fibras de vicuña, guanaco y llama, además de chinchilla, vizcacha y zorro. Como se puede observar, la producción de lana no parecería ser la función principal de la llama, sólo debieron ser trasquilados aquellos animales que no fueron usados para el transporte. La evidencia sugiere que la llama sería el medio por el cual la población de este yacimiento explotó el medio ambiente con el fin de poder acceder a una mayor variedad de recursos a través del transporte e intercambio. Así la dieta es complementada, además, con productos provenientes de la costa, representados por vértebras de pescado y restos de moluscos. En cuanto a los artefactos líticos, han aumentado los implementos de molienda y aparecen pequeñas palas agrarias; sin embargo, no se encuentran restos de semillas. Las palas son muy pequeñas en relación a las que se encuentran en períodos más tardíos (Benavente com. pers. 1992).

Si bien la recolección y manipulación no estuvo ausente del grupo, la subsistencia sigue concentrándose en el recurso animal. Tampoco se encontraron neonatos que puedan sugerir una ocupación acotada; la presencia de individuos menores de nueve meses permite postular una ocupación durante el otoño, invierno y primavera. Al respecto, Benavente (1981) plantea que durante la estación de invierno los animales aprovecharon los pastos ofrecidos por vegas y cañones, subiendo en verano a nichos superiores de precordillera y Puna.

El análisis de las frecuencias de unidades anatómicas, expresadas en términos de \% MAU, permitió visualizar una representación similar para el miembro posterior y anterior superior incluidas la escápula y la pelvis; luego con menor frecuencia, vértebras cervicales, patas bajas, cráneo, costillas vértebras lumbares y toráxicas. En este sitio, todas las unidades anatómicas se encuentran representadas, lo que sugiere un sacrificio y faenamiento de animales domésticos cercano a las unidades residenciales a la vez que la entrada de unidades de trozamiento de animales silvestres. Dentro de las unidades se producirían eventos de consumo y de faenamiento secundario. Sin embargo, no parece clara la manufactura de charqui propuesta por Yacobaccio y Madero (1988); de ser posible ésta, involucraría las costillas que no alcanzan una representación alta.

El faenamiento se da por medio de la desarticulación. La baja presencia de atlas con respecto al axis podría sugerir que éste es destruido en el momento del sacrificio o que queda junto al cráneo, de tratarse de un sacrificio como el "degüello ventral". Miller (1977) lo resume como el corte del cuello por el lado ventral hasta la tráquea y el esófago, rompiendo por último la médula espinal, dando el corte entre el atlas y los cóndilos occipitales, degüello que también puede dejar marcas en las vértebras cervicales (Benavente 1981). Otro tipo de sacrificio es la "puntilla dorsal" (Miller 1977) que consiste en una cuchillada rápida entre los cóndilos occipitales y el atlas cortando la médula espinal. Sin embargo, en el registro sólo se encuentran marcas en algunas facetas articulares de vértebras cervicales y, por tanto, no se puede precisar la forma en que fue muerto el animal.

También se presentan huesos largos fracturados producto de la extracción de médula. La fractura mejor representada es la longitudinal, sobre todo en las primeras falanges, seguida por la transversal y oblicua. La primera falange se presenta altamente quebrada con tipos de fractura similares a las vistas en Chiu Chiu Cementerio, no así la segunda falange. Las actividades de manufactura, faenamiento y consumo están evidenciadas, además, por los artefactos líticos de los cuales cuchillos, raederas y lascas utilizadas como instrumento de corte alcanzan una alta representación. También se presentan percutores, buriles y taladros que "responden a actividades como son la preparación de materias primas (cuero y carnes), sacrificio y descuartizamiento de animales" (Benavente 1981: 112).

Los restos óseos analizados corresponden a tres unidades habitacionales que conforman un mismo patrón, las tres presentan sus muros colindantes en una línea orientada norte-sur, es decir, la delimitación norte de la primera estructura conforma el muro 
sur de la siguiente. Los muros en el lado oeste se presentan más densos y altos, lo que podría sugerir que la entrada se encuentra hacia el sureste.

Todas las estructuras presentan densas concentraciones de restos óseos en los muros, especialmente la del medio y la de más al norte. Se detectaron en cada una de ellas lentes de ceniza y piedras calcinadas que señalarían la existencia de pequeños fogones para cada unidad habitacional. Los fragmentos quemados (que alcanzan un 26\%) son depositados en los muros contiguos a los fogones.

Cada estructura representaría unidades habitacionales donde se llevó a cabo el consumo, junto a actividades de manufactura. En la estructura situada más al norte, junto a otros artefactos óseos, se encontró un pulidor de cerámica confeccionado a partir de un fragmento de tibia. Este podría estar relacionado con la confección de cerámica, si se considera que "las clases alisadas, pulidas y pintadas por la técnica de manufactura y tratamiento de superficie, correspondan a los tipos confeccionados por el grupo en la localidad" (Benavente 1981: 110). Se encontró, además, un punzón con huellas de uso que debe haber sido utilizado con materiales abrasivos. En general, la unidad situada más al sur presenta menor cantidad de restos óseos que las otras dos. Cabe señalar que se encontraron restos de paja que corresponderían a parte de la techumbre de las estructuras.

De acuerdo al análisis de la ubicación y representación de los restos óseos, Benavente (1981: 90) señala que:

"cada unidad familiar mantenía un número determinado de animales evidenciado por la cantidad de restos óseos en los basureros como materias para su sacrificio, despostamiento y faenamiento, materia prima y textil, items presentes en cada una de las habitaciones excavadas, lo que en conjunto conforman los bienes de cada unidad residencial."

En comparación con Chiu Chiu Cementerio las estructuras son más pequeñas, es decir, corresponderían a unidades familiares, que, si bien viven más aglutinadas, cada una realiza las tareas en su unidad habitacional como, por ejemplo, la preparación de alimentos. Cabe señalar que la representación de las unidades anatómicas sugiere que éstas ingresan a la unidad para ser consumidas, no evidenciando la posterior dispersión de éstas fuera del asentamiento original luego del primer consumo por confección de charqui u otros mecanismos. La ausencia de corrales permite suponer la pastura conjunta del ganado en la vega. Alrededor de este poblado central existiría una serie de sitios de actividad evidenciados en diversos puntos de la vega (Benavente 1981).

La estructura social parece mantenerse bastante igualitaria pese a que la mantención de rebaños pudiera representar diferencias entre los elementos del contexto. Estas últimas podrían impulsar el intercambio con el fin de obtener objetos de estatus (p. e., plumas de aves tropicales, Benavente 1989Ms). No obstante, los objetos y productos del intercambio guardan más bien relación con las necesidades generales de la población, como lo evidencian restos de pescados y conchas encontrados. Si bien en el aspecto textil hay diferencias en la calidad de los tejidos, éstas estarían dadas por el uso diferenciado de éstos, existiendo por una parte los destinados a funciones de carga y transporte (redes y mallas) y, por otra, los tejidos planos como felpudos y emplumados para prendas. Estos últimos se asociarían más bien con el intercambio ya que "debido a la materia prima empleada en su confección (chinchilla y plumas) definen a estos objeto como preciado elemento de intercambio para las poblaciones del área y áreas aledañas" (Benavente 1981: 106).

\section{Conclusiones}

Hacia 2165 AC hay clara presencia de llama en Chiu Chiu Cementerio, lo que evidencia la domesticación de esta especie, pero no de carácter experimental, sino más bien inicial o temprana, con funciones zootécnicas delimitadas para cada especie doméstica o silvestre.

La presencia de esta especie doméstica no significa un quiebre entre los grupos cazadores recolectores y aquellos que manejan animales domésticos, quienes siguen manteniendo estrategias de caza y recolección como respuesta a las condiciones ambientales y culturales (Bender 1975). Berwick (1975: 135) señala que "el hombre ve su medio a través de cristales teñidos culturalmente. Los recursos se seleccionan en base a los valores culturales de una sociedad con un nivel muy especial de tecnología”.

Se puede hipotetizar que si bien para los habitantes de Chiu Chiu 200 insertos en un ambiente de oasis:

"donde los recursos ofrecidos a la población han carecido de la variedad suficiente y necesaria para la población allí asentada, ésta, ante la restricción del medio para poder explotarlo y a su vez procurarse 
la variedad necesaria a su subsistencia, recurrió a la actividad pastoril la cual daba la movilidad necesaria para intercambiar productos con otros medios ambientes aledaños" (Benavente 1981: 118).

Esta forma de adaptación ya podría estar delineada por los habitantes de Chiu Chiu Cementerio. En términos del material cultural, existirían algunos elementos que podrían sustentar cambios, ya que no tienen antecedentes en el área.

La llama presenta un patrón de crianza de animales adultos. Una llama adulta puede ser útil para el transporte y en segundo término, para lana. Pero, como fue señalado, la población tenía un conocimiento del manejo de fibras textiles y privilegió las fibras lanígeras mejores (como vicuña).

Como postula Spooner (1973), aquellos grupos que subsisten directa o indirectamente de los animales domésticos no pueden vivir solamente con una dieta tan restringida, ya sea los complementan con cultivos propios o recurren al intercambio. Ferraz (1992Ms-a, 1992Ms-b) señala que para este sitio las evidencias de utilización vegetal están bajamente representadas, pero no así en el caso de restos de pescados y moluscos, productos provenientes de la costa.

La adopción de animales domésticos no transforma instantáneamente la vida o eleva automáticamente el nivel de vida (Bender 1975: 5). Coincido con Browmann (1974, 1976, en Druss 1980) en cuanto a que la domesticación es un proceso conservativo, que preserva la estructura económica de grupos cazadores recolectores y, como señala Hesse (1982), es necesaria una reorientación de los valores sociales asociados a la caza y recolección, hacia el pastoreo.
Chiu Chiu 200, separado por un período de 1000 años, presenta un registro arqueofaunístico muy similar al de Chiu Chiu Cementerio. Si los cambios no se perciben en este tipo de registro (salvo diferencias de tamaño, fracturas u otras), éstos se dan en otros ítems, generando grandes diferencias contextuales dadas por la aparición de cerámica, diferencias en la tipología lítica, excelencia textil, presencia de cestería y la conformación y distribución de sus estructuras. Sin embargo, lo interesante de estos nuevos rasgos es que son más bien producto de contacto con grupos de áreas aledañas (Benavente 1981, 1989Ms) ya que han aumentado el espacio e intensidad de los contactos, pero sobre una matriz previa formada por los grupos pertenecientes al Arcaico Tardío. Estos, según Mena (1981), están sujetos a una compleja relación dinámica entre grupos con un alto nivel de movilidad y de un medio ambiente cambiante y diversificado. El Complejo Chiu Chiu se presentaría como una intersección de una serie de vías de tránsito. Por consiguiente, sobre estos grupos estarían operando una serie de influjos que generan cambios, en contraposición a un modelo de evolución lineal donde los grupos se ven como una variable aislada.

Comparto, por último, el modelo propuesto por Wheeler y colaboradores (1977a: 158) para describir la utilización de los animales en sociedades cazadoras-pastoras. Este se caracterizará "por la caza de camélidos salvajes como por el pastoreo, conjuntamente con una insignificante utilización de otras especies. Se presume que la caza del guanaco y vicuña fue siempre practicada, uno por su preciada carne y la otra por su fina lana". La llama esboza una utilización que tendería a la función de carga $\mathrm{y}$ transporte con el fin de superar las restricciones del medio ya hacia $2165 \mathrm{AC}$.

\section{REFERENCIAS CITADAS}

ADARO, L. y A. BENAVENTE, 1990. Identificación de patrones óseos de camélidos sudamericanos. Avances en Ciencias Veterinarias 5 (2): 79-86.

- 1992a. Manual osteológico de camélidos sudamericanos (Mimeo). Universidad de Chile, CONAF.

_ 1992b. Atlas osteológico taruca del norte (Hippocamelus Antisensis) (Mimeo). Universidad de Chile, CONAF.

ARIAS, G., A. BENAVENTE y P. GECELE, 1992Ms. Identificación y variabilidad del uso animal, a través de textiles arqueológicos: Contraste con patrones fanéreos actuales. Informe Proyecto FONDECYT 792-89.
ASCHERO, C., D. ELKIN y E. PINTAR, 1991. Aprovechamiento de recursos faunísticos y producción lítica en el precerámico tardío. Un caso de estudio: Quebrada Seca 3 (Puna meridional de Argentina). Actas del XI Congreso Nacional de Arqueología Chilena (1988), pp. 104-114. Santiago.

BEHRENSMEYER, A., 1978. Taphonomic and ecologic information from bone weathering. Paleobiology 4 (2): 150-162.

BENAVENTE, A., 1981. Chiu Chiu 200: Un campamento de pastores. Tesis para optar al grado de Licenciado en Arqueología y Prehistoria. Universidad de Chile, Santiago. 
1984. Chiu Chiu 200: Una comunidad pastora temprana en la Provincia del Loa (II Región). Actas del IX Congreso Nacional de Arqueología (1982), pp. 75-94. La Serena.

1985. Reflexiones en torno a la domesticación en los valles del centro y sur de Chile. Boletín del Museo Regional de la Araucanía 2: 37-52.

1988-89. Nuevas evidencias arqueológicas acerca de los asentamientos tempranos en el Loa Medio. Paleoetnología 65-72.

— 1989Ms, 1990Ms, 1992Ms. Un enfoque arqueozoológico para la identificación de restos óseos de camélidos sudamericanos. Informes preliminares (Proyecto FONDECYT 792-89).

1992. Determinación de especies de camélidos sudamericanos. Un enfoque arqueozoológico. Revista Chilena de Antropología 11: 41-59.

BENAVENTE, A. y L. ADARO, 1992. Identificación de patrones óseos de camélidos sudamericanos. Avances en Ciencias Veterinarias 7 (1): 27-35.

BENAVENTE, A., L. ADARO e I. CARTAJENA, 1990. Identificación de especies de camélidos sudamericanos a través de un enfoque arqueozoológico. Jornada Nacional de Anatomistas, pp. 36-38. Sociedad Chilena de Anatomía, Santiago.

BENAVENTE, A., L. ADARO y P. GECELE, 1993. Contribución a la determinación de animales en arqueología: Familia $\mathrm{Ca}$ melidae y Taruca del norte. Serie Programas de Desarrollo, vol. 3. Universidad de Chile, Santiago.

BENDER, B., 1975. Farming in prehistory (from hunter-gatherer to food producer). St. Martin's Press, Nueva York.

BERWICK, D. E., 1975. Valoración del análisis sistemático de los restos de la fauna en sitios arqueológicos. Chungara 5: $125-140$.

BINFORD, L., 1981. Bones: Ancient men modern myths. Academic Press, Nueva York.

BINFORD, L. y J. B. BERTRAM, 1977. Bone frequences and attrincional processes. En For theory building in archaeology. Essays of faunal remains, aquatic resources, spatial analysis and systemic modeling, pp. 77-152. Academic Press, Nueva York.

CARDICH, A. y A. LAGUENS, 1984. Fractura intencional y posterior utilización del material óseo arqueológico de la Cueva Los Toldos, Provincia de Santa Cruz, Argentina. Revista del Museo de La Plata. Antropología VIII (63): 329-383.

CARTAJENA, I., 1991Ms. Un enfoque arqueozoológico para la clasificación de restos óseos de camélidos. Práctica Profesional. Universidad de Chile, Santiago.

1993. Determinación de restos de camélidos en dos yacimientos del Loa Medio (II Región). Memoria para optar al Título de Arqueólogo. Universidad de Chile, Santiago.
CARDOZO, A., 1954. Auquénidos. Editorial Centenario, La Paz.

DRUSS, M., 1980. The oasis theory revisted: Variation in the subsistence-settlement of the final Preceramic Chiu Chiu Complex, Northern Chile, and its implications for the process of Andean Camelid domestication. $33^{\circ}$ Northwest Anthropological Conference Bellingham, Washington.

FERNANDEZ DISTEL, A., 1974. Excavaciones arqueológicas en las cuevas de Huachichocana. Departamento de Tumbaya, Prov. de Jujuy, Argentina. Relaciones de la Sociedad Argentina de Antropología 8: 101-127.

FERRAZ, J., 1992Ms-a. Estudio crítico del material lítico del sitio Chiu Chiu Cementerio (Arcaico Tardío): Resultados preliminares. Informe FONDECYT 792-89.

1992Ms-b. Informe preliminar estudio del material lítico de una estructura habitacional del sitio arcaico tardío Chiu Chiu Cementerio. Informe FONDECYT 792-89.

GRIGSON, C., 1978. Towards a blueprint for animal bone reports in archaeology. Research problems in zooarchaeology. Occasional Publication 3: 121-127.

HABER, A. y N. RATTO, 1988. De procesos, contextos y otros huesos. En Seminario de actualización en arqueología. Análisis de vertebrados e invertebrados de los sitios arqueológicos, pp. 1-8. Universidad de Buenos Aires, Buenos Aires.

HAYNES, G., 1983. Frequencies of spiral and greenbone fractures on ungulate limb bones in modern surface assemblages. American Antiquity 48 (1): 102-114.

HERRERA, O., 1988. Los camélidos y sus indicadores óseos de estacionalidad: Apuntes para la discusión. En Seminario de actualización en arqueología. Análisis de vertebrados e invertebrados de los sitios arqueológicos, pp. 101-110. Universidad de Buenos Aires, Buenos Aires.

HESSE, B., 1982. Animal domestication and oscillating climates. Journal of Ethnobiological 1: 1-15.

1986. Buffer resources and animal domestication in prehistoric Northern Chile. Archaeozoologia Melanges 73-85.

HESSE, B. y P. HESSE, 1979Ms. Archaic animal exploitation in inland Northern Chile.

JACKSON, D., 1989Ms-a. Caracterización del componente lítico de la comunidad de pastores de Chiu Chiu 200, Provincia del Loa (II Región). Informe FONDECYT 792-89.

1989Ms-b. Proposición metodológica para establecer diferencias y definir la base subsistencias de grupos agroganaderos en base a instrumentos líticos. Informe FONDECYT 792-89.

JACKSON, D. y A. BENAVENTE, 1989Ms. Caracterización del instrumental lítico de la comunidad de pastores Chiu Chiu 200, Provincia del Loa (II Región). Informe FONDECYT 792-89. 
- 1990Ms. Estudio de una estructura habitacional tardía de Chiu Chiu Cementerio, Provincia de El Loa. Informe FONDECYT 792-89.

1992Ms. Secuencia, cambios y adaptación de los cazadores recolectores de la microcuenca Chiu Chiu, Provincia de El Loa. Informe FONDECYT 792-89.

KENT, J., 1986. The domestication and exploitation of South American camelides. Methods of analysis and their application to circumlacustrine archaeological sites in Bolivia and Peru. Washington University. University Microfilms International.

KLEIN, R. G. y K. CRUZ URIBE, 1984. The analysis of animal bones from archaeological sites. The University of Chicago Press, Chicago.

LANATA, L., 1988. Huesos quemados, huesos contados. En Seminario de actualización en arqueología. Análisis de vertebrados e invertebrados de los sitios arqueológicos, pp. 75-90. Universidad de Buenos Aires, Buenos Aires.

LEGGE, A. J., 1978. Archaeozoology or zooarchaeology. Occasional Publication 3: 129-131.

LOWNIE, H., 1978. Research problems in zooarchaeology. Occasional Publication 3.

MENA, F., 1981. Consideraciones en torno a la movilidad de grupos en el Arcaico Tardío, II Región. Tesis de grado para optar al Título de Licenciado en Arqueología y Prehistoria. Universidad de Chile, Santiago.

MENGONI, G., 1982. Notas zooarqueológicas I. Fracturas en huesos. VII Congreso Nacional de Arqueología. Colonia del Sacramento.

1988a. Análisis de materiales faunísticos de sitios arqueológicos. XAMA. Publicaciones de la Unidad de Antropología, pp. $71-120$.

- 1988b. El estudio de huellas en arqueofauna, una vía para reconstruir situaciones interactivas en contextos arqueológicos: Aspectos teóricos y técnicas de análisis. En Seminario de actualización en arqueología. Análisis de vertebrados e invertebrados de los sitios arqueológicos, pp. 17-28. Universidad de Buenos Aires, Buenos Aires.

MILLER, G., 1977. Sacrificio y beneficio de camélidos en el sur de Perú. En Pastores de Puna, J. Flores Ochoa (Ed.), pp. 193210. Instituto de Estudios Peruanos, Lima.

MUNIZAGA, J., 1992Ms. Restos óseos humanos precolombinos. Sitio Chiu Chiu Cementerio. Informe final Proyecto FONDECYT 792-89.

NUÑEZ, L., 1982. Asentamientos de cazadores recolectores tardíos en la Puna de Atacama: Hacia el sedentarismo. Chungara 8: $137-168$.

1983. Paleoindio y Arcaico en Chile. Escuela Nacional de Antropología e Historia, México D. F.
1992. Ocupación arcaica en la Puna de Atacama: Secuencia, movilidad y cambio. En Prehistoria sudamericana. Nuevas Perspectivas, pp. 283-308. Editorial Universitaria, Santiago.

NUÑEZ, L. y C. SANTORO, 1988. Cazadores de la Puna Seca y Salada del Area Centro Sur Andina (norte de Chile). Estudios Atacameños 9: 11-60.

NUÑEZ, L., J. VARELA y R. CASAMIQUELA, 1987. Ocupación paleoindia en el centro-norte de Chile: Adaptación circumlacustre en las tierras bajas. Estudios Atacameños 8: 142-185.

ORELLANA, M., 1971. Informe de las excavaciones de Loa Oeste. Boletín de Prehistoria de Chile 3 (4): 3-26.

PACHECO, V. y otros, 1979. Guía osteológica para camélidos sudamericanos. Serie Investigaciones 4. Universidad Nacional Mayor San Marcos, Lima.

PIRES-FERREIRA, E., J. WHEELER y P. KAULICKE, 1977. Utilización de animales durante el Período Precerámico en la cueva de Uchumachay y otros sitios de los Andes Centrales de Perú. Journal de la Société des Américanistes LXIV: 149-144.

POLLARD, G. C., 1982. The cultural ecology of ceramic stage settlement in the Atacama Desert. University Microfilms Inc., Ann Arbor, Michigan 1971. Printed by Microfilm.

POLLARD, G. e I. DREW, 1975. Llama herding and settlement in prehispanic Northern Chile: Application of an analysis for determinig domestication. American Antiquity 40 (3): 296-305.

SCHIFFER, M., 1976. Behavioral archaeology. Academic Press.

SPOONER, B., 1973. The cultural ecology of pastoral nomads. An Addison-Wesley Module in Anthropology 45

WHEELER, J., 1982. Aging llamas and alpacas by their teeth. Llama World 1 (2): 12-17.

WHEELER, J. y E. MUJICA, 1981Ms. Prehistoric pastoralism in the lake Titicaca Basin, Perú, 1979-1980 field season. Final Report.

WHEELER, J., E. PIRES-FERREIRA y P. KAULICKE, 1977a. Domesticación en los Andes Centrales durante el Período Precerámico: Un modelo. Journal de la Société des Américanistes. XIV: 155-165.

WHEELER, J., R. CARDOZZA y E. POZZI, 1977b. Estudio provisional de la fauna de las capas II y III de Telarmachay. Revista del Museo Nacional 43: 97-102.

WING, E., 1972. Utilization of animal resources in the Peruvian Andes. En Andes 4, Excavations at Kotosh, Perú 1963 and 1969, S. Izumi y K. Terada (Eds.), pp. 327-350. University of Tokio Press, Tokio.

1975. La domesticación de animales en los Andes. Allpanchis VIII 8: 25-44 
1977. Caza y pastoreo tradicionales en los Andes. En Pastores de Puna, J. Flores Ochoa (Ed.), pp. 121-130. Instituto de Estudios Peruanos, Lima.

YACOBACCIO, H. D., 1988. Camélidos, domesticación y tamaño de la muestra: Reflexiones sobre la utilización animal prehistórica en los Andes. En Seminario de actualización en arqueología. Análisis de vertebrados e invertebrados de los sitios arqueológicos, pp. 61-100. Universidad de Buenos Aires, Buenos Aires.
— 1991. Tesis Doctoral.

YACOBACCIO, H. y C. MADERO, 1988. ¿Qué hacían los pastores con los huesos? Precirculados de las ponencias presentadas en el IX Congreso Nacional de Arqueología Argentina, pp. 64-74. Universidad de Buenos Aires, Buenos Aires. 